\title{
The role of public information in corporate social responsibility*
}

\author{
Aleix Calveras ${ }^{\dagger} \quad$ Juan-José Ganuza ${ }^{\ddagger}$ \\ This Draft: February 6th, 2015.
}

\begin{abstract}
Many of the attributes that make a good 'socially responsible' are credence attributes that cannot be learned by consumers either through search or experience. Consumers, then, use for their purchasing decisions 'noisy' information about these attributes obtained from potentially contradictory channels (media, advertisement, NGOs). In this paper we model such informational framework and show the positive relationship between the accuracy of the information transmitted to consumers and corporate social responsibility (CSR). We also show that a firm may be tempted to add noise to the information channel (through lobbying of the media), which might reduce the supply of the CSR attributes and even harm the firm itself (with lower profits). It might then be profitable to the firm to commit ex-ante to not manipulate the information regarding the firm's business practices (e.g., with a partnership with an NGO). Finally, we extend our model to a competition framework endogenizing the number of firms active in the CSR segment. We show both that in more transparent markets a larger number of firms will be CSR, and that in a market with more intense competition, a higher degree of transparency is required in order to sustain a given number of CSR firms.
\end{abstract}

JEL classification numbers: D72, H42, L51, M14, Q52.

Key words: credence good, information asymmetry, corporate social responsibility, regulation, NGO, competition.

${ }^{*}$ We are grateful for comments by the co-editor, two anonymous referees, seminar participants at FEDEA and Universidad de Salamanca, and the conference attendees at the JEI (Madrid) and the EARIE conference (Istambul). Naturally, all errors are ours. Aleix Calveras gratefully acknowledges financial support of the Spanish Ministry of Science and Technology under grant ECO2013-48496-C4-1-R. Juan-José Ganuza gratefully acknowledges the support of the Barcelona GSE Research, the government of Catalonia, and the Spanish Ministry of Education and Science Through Project ECO 2011-28965.

${ }^{\dagger}$ Department of Business Economics, Universitat de les Illes Balears. Cra Valldemossa Km 707122 Palma de Mallorca, Spain. E-mail: aleix.calveras@uib.es.

${ }^{\ddagger}$ Department of Economics and Business, Universitat Pompeu Fabra. C/ Ramon Trias Fargas 25-27 08005 Barcelona, Spain. E-mail: juanjo.ganuza@upf.edu. 


\section{INTRODUCTION}

Many of the attributes that make a good or a service "green" or, more generally, socially responsible, are credence attributes, not directly observable by consumers, who cannot learn about them either through search or experience (Nelson, 1970; Tirole, 1988; Baron, 2011). Examples of such attributes are numerous: the conditions under which the product is produced (including any externalities associated with production, e.g. pollution and how workers are treated and how well they are paid), hidden hazards associated with consumption of the product, etc.

This asymmetry of information between a firm and its customers (and other stakeholders) regarding the firm's business practices poses a threat to the viability of corporate social responsibility (CSR). ${ }^{1}$ CSR is mainly driven by demand of "conscious" consumers (namely, consumers who value one of these CSR credence attributes, and are willing to pay a higher price for a good that includes them) and, thus, the level and accuracy of the information available to consumers is key. ${ }^{2}$ Absent credible information, the market might fail to provide the credence attributes valued by consumers: if consumers are uncertain about the attributes of the good, then they might not be willing to pay a premium for it and, thus, firms will not supply such attributes in the first place (Akerloff, 1974). Thus, the level of credible information available to consumers (firm's stakeholders in general) with respect to firm's business practices is key in the development of CSR. And the purpose of this paper is precisely to study the role of informational issues in the promotion of CSR. More specifically, we want to analyze:

(i) In which way the level of information accuracy (or lack of it) in the market impacts in the ability and incentives of firms to invest in corporate social responsibility. We consider that consumers receive information from several channels (with potentially contradictory messages; e.g. from the media, NGOs, and firms themselves) and that they aggregate it in a noisy signal.

\footnotetext{
${ }^{1}$ By corporate social responsibility we denote those "voluntary actions that firms take over and above compliance with minimum legal requirements, to address both its own competitive interests and the interests of the wider society" (as defined by the UKs Department of Trade and Industry).

${ }^{2}$ Evidence regarding the valuation by some conscious consumers on some credence attributes (and who are willing to pay a higher price for them) can be found in relation to the labor conditions of a firm (Hiscox and Smyth, 2009), to charity linked products (Elfenbein and McManus, 2007), or the environmental friendliness of a product (Casadesus-Masanell et al., 2009). See also, for instance, Mohr et al., 2001, and Murray and Volgel, 1997).
} 
It is thus important to assess in which way the quality of the signal impacts on firms' incentives to invest in social responsibility, and we do so considering different levels of market competition among CSR firms.

(ii) How information about the behavior of the firm is produced and the incentives of agents to provide it. The number of agents that (may) play a role in the transmission of information to consumers on businesses' practices is wide; in particular, we focus on the incentives of a firm to manipulate the information provided to consumers (through advertisement, media, etc.) and the consequences it has on CSR.

(iii) The role of regulation and, specially, other decentralized institutional arrangements such as a firm's partnership with an NGO, in order to promote transparency and indirectly foster $\mathrm{CSR}^{3}$

Our modelling framework thus allows us to discuss in which way the accuracy of the information that consumers receive influences the incentives of firms to be CSR, specifically by investing in a clean and more expensive technology (rather than in the standard, dirty and cheaper one). We do the analysis first in the benchmark model in which only a single firm may differentiate and become CSR, and then also in a framework where we endogenize the number of firms that may differentiate and become CSR. When competition in CSR is considered, in addition to the impact of market transparency, we analyze the effect that the intensity of competition (e.g. à la Bertrand v. collusive pricing) has on the overall industry's level of CSR. We show that, intuitively, both in the single firm as well as in the multiple firms framework, the higher the accuracy of the information provided to consumers on the true technology used by the firm (higher market transparency), the more incentives firms have to invest in social responsibility by investing in the clean technology. Thus, with higher market transparency, the number of firms that will be CSR is larger. The intuition is straightforward: only when there is enough information regarding the

\footnotetext{
${ }^{3}$ An example of a transparency regulation is the European Union Directive 1999/94/EC which requires car makers to inform consumers on fuel economy and CO2 emissions of each car, as part of a "an overall Community strategy aimed [...] to reduce CO2 emissions, in particular those caused by passenger cars" (EU Directive 1999/94/EC). More specifically, the labelling Directive requires the display of a label on fuel consumption and CO2 emissions on all new cars, the publication of national guides on the fuel efficiency and emission of CO2 of new cars, the display of posters at the dealerships and the inclusion of fuel efficiency and CO2 emissions information in printed promotional literature.
} 
practices followed by firms, will consumers be willing to pay a higher price for a good labeled as socially responsible, in which case firms then have incentives to undertake socially responsible investments. ${ }^{4}$ We also show that an increase in the intensity of competition among CSR firms decreases firms' incentives to invest in CSR (see Bagnoli and Watts, 2003, and Fernandez and Santalo, 2010). The rationale is the so-called 'margin effect' whereby more intense competition reduces the margin to be gained from an investment in CSR.

Our paper also includes an analysis of the informational channel between a firm and consumers (and possibly other agents). More specifically, we analyze the incentives of a firm to provide information and show that, if possible, the firm would manipulate (e.g., through advertisement) the information provided to consumers, hence increasing the probability of a non CSR behavior to go undetected. Such manipulation, however, by decreasing the accuracy of the information provided to consumers, might destroy the incentives of the firm to invest in CSR technologies. Thus, the possibility to manipulate might eliminate the possibility of an equilibrium with the clean CSR technology.

Moreover, such manipulation might even harm the firm itself (lowering its profits) and, as a consequence, in some cases the firm would like to be able to commit ex ante not to manipulate the information provided to consumers (or, in other words, to increase the accuracy of the information provided to the public). For the firm, a way to commit might imply the involvement of the firm with a third party (such as an NGO) whose independent reputation might inform in a credible way that the firm does not manipulate and, thus, increase the accuracy of the signal received by consumers. This result might illustrate one of the rationales behind many partnerships we see in real life between firms and NGOs; e.g., Starbucks with the environmental NGO Conservation International, or the partnership between the multinational fruit company Chiquita with the NGO Rainforest Alliance.

\footnotetext{
${ }^{4}$ The link between market transparency and CSR provides a rationale for many forms of transparency regulations present in the markets, such as the European Directive 1999/94/EC explained above. Such a Directive has the explicit aim both of increasing the consciousness of consumers and of allowing already conscious consumers to take informed decisions in accordance to their preferences, thus giving incentives to firms to sell less polluting cars. This fits well within our analysis since we also show that the more consciousness consumers are, the more incentives a firm has to invest in socially responsibility.
} 


\subsection{Related Literature}

We model CSR as the supply by the firm of a socially responsible credence attribute attached to a private good (as in Baron, 2011). ${ }^{5}$ Many markets of credence goods have been analyzed: see, for instance, Emons, 1995, and Wolinsky, 1993, 1995, on car repair services, taxi cab ride and medical treatments. More recently, Dulleck and Kerschbamer (2006) show that (similarly as in the Akerlof, 1970, lemons model), when "consumers can neither observe the type of treatment [CSR attribute] they get, nor can they punish the expert [the firm in our set-up] if they realize ex post that the type of treatment they received is not sufficient", then no trade will take place and the credence good market ceases to exist (Dulleck and Kerschbamer, 2006, page 29). Notice this is precisely the situation of CSR as a credence attribute attached to a private good. As a consequence, as we model in our framework, the only way CSR may be part of an equilibrium is when information is provided by a third party (such as the media, an NGO, etc.).

There exist in the market several institutions designed to cope with the lack of information by consumers on the credence attributes supplied by firms (i.e., the social responsibility of firms' practices). These institutions include certifications, whether provided by a single firm (Bottega and de Freitas, 2008) or a group (club) of them (Baron, 2011); the information provided by activists such as NGOs (Feddersen and Gilligan, 2001) in the context of private politics (Baron, 2003, 2005); direct (advertisement) or indirect communication by firms; and information provided to consumers/citizens by the media (Dyck and Zingales, 2002). Previous literature mostly focuses on one of these institutions and assumes that such institution may solve completely the information asymmetry. One such analysis is about certification and eco-labels. Bottega and de Freitas (2009), for instance, analyze certification by a third party (either a private firm or an NGO) which credibly informs (with certitude) about the credence attribute that the firm is supplying, and study the effect it may have on the scope for public regulation. In their framework, thus, informational accuracy and manipulation is not an issue. The same, for instance, can be said about Baron

\footnotetext{
${ }^{5}$ This is analogous to the modeling of CSR as the provision by firms of a public good jointly with a private good (as in Besley and Ghatak, 2007, and Bagnoli and Watts, 2003).
} 
(2011) which analyzes the supply of credence attributes by firm members of a club (a voluntary organization) that is in charge of verifying that the established standard is met.

The impact of (the intensity of) competition on CSR by firms has been analyzed before. Bagnoli and Watts (2003) show that an increase in the intensity of competition in the industry (competition à la Bertrand instead of à la Cournot) reduces CSR by firms. Their result arises through the effect that a reduction in competition in the (no-CSR) private good market has on the CSR segment: an increase in the price of the no-CSR segment increases the demand (and thus supply) of the CSR goods. This mechanism is not present in our framework where we always assume perfect competition in the no-CSR market segment. Our result, instead, is mainly driven by the 'margin effect' as Fernandez and Santalo (2010) call it, whereby a more intense competition in the product market reduces margins obtained by firms and therefore their incentives to invest in CSR as a way to increase revenues. Fernandez and Santalo (2010) do analyze empirically the relationship between market competition and CSR by firms and show that CSR is positively correlated with market competition, evidence of the 'business-stealing effect', that is, firms' incentives to invest in CSR in order to increase market share. Besley and Ghatak (2007) analyze the feasibility of CSR by firms when there is competition among CSR and no-CSR firms, showing that CSR firms may indeed exist in a competitive equilibrium. Pecorino $(2009,2013)$ analyzes the impact that monopolistic competition have on by-product firms (that sell a private good and use their profits to provide a public good), showing that if the number of by-product firms is proportional to the size of the society, then public good provision (CSR) rises without bound as the society grows large. All such analysis assumes perfect information, while we are the first to incorporate market transparency and informational uncertainty in the analysis of CSR as credence attributes and competition. Fisman et al. (2006) do look at the impact of competition in CSR in a reduced form model with only two firms; in their model à la Hotelling, however, CSR by the only firm that can be socially responsible is used as an observable signal of unobservable product quality (as in Calveras and Ganuza, 2014). This observability of CSR and its use as a signal of unobservable underlying product quality is also the focus of analysis in Elfenbein et al. 
(2012). What is similar to our analysis is their assumption that different sellers present different disutilities from behaving opportunistically (analogous to our three types of fixed costs of firms), which they correlate with the seller's utility from charitable giving, allowing for the observable charities to be used as a signal of unobservable product quality.

Our paper is also the first one to discuss the incentives of a firm to invest in corporate social responsibility in a context in which the firm may manipulate the information provided to consumers. There are many papers dealing with the manipulation of information by agents ${ }^{6}$. In the context of persuasive games, and within the literature of CSR, Lyon and Maxwell (2011) discusses 'greenwash', namely, the selective disclosure of positive information about a firm's social performance, without full disclosure of negative information on these dimensions. Our analysis models in a reduced form the manipulation of information, and analyses its interaction with firm's incentives to invest in CSR and its corresponding social performance, something not done in Lyon and Maxwell (2011).

Feddersen and Gilligan (2001) also analyze the role that an NGO (activist) may play in a market for CSR credence goods. As we do, they find that the presence of an activist may increase market transparency and, accordingly, may support equilibria with CSR which in the absence of the activist would not arise. Their analysis considers competition between two firms and one strategic activist that may monitor one firm and inform potential customers. In our framework with one firm, instead, the activist is rather passive, simply a commitment device to the firm; we do consider, however, that the firm may manipulate the information available to customers, an action that firms in Feddersen and Gilligan (2001) cannot do. Additionally, in our analysis with competition we are able to study the relationship between the level of competition in CSR and market transparency, an avenue not studied by Feddersen and Gilligan (2001).

Finally, a recent and related paper to our single firm analysis is Bagnoli and Watts (2014) which presents a signaling game studying a firm's decision to engage in CSR, voluntarily report

\footnotetext{
${ }^{6}$ See for example, the cheap talk literaure, where informed agents may lie (Crawford and Sobel, 1982; Farrell and Rabin (1996), etc.), and in persuasive games, where informed agents only may hide information (Dye, 1985; Glazer and Rubinstein, 2004; Grossman, 1981; Shin, 1994; etc).
} 
on it and purchase external assurance of the report. While Bagnoli and Watts (2014) follows a different modeling strategy (they use a reduced form of the market game), their results are similar to ours: incentives to engage in CSR depend on the accuracy of the information held by consumers, and this accuracy can be affected by firms' actions (manipulation or voluntary reports) as well as by third parties that can sustain CSR separating equilibria. In the analysis of this separating equilibrium, they highlight the complementarity between voluntary and involuntary actions, while we focus on the impact of firm's commitment by means of third parties over total welfare.

In section 2 we present the benchmark model which we solve in section 3, obtaining and discussing proposition 1,2 and 3, namely, the role of the accuracy of information and the consciousness of consumers in the promotion of CSR, as well as a welfare analysis. Next, in section 4, we endogenize information, first by studying the firm's incentives to manipulate such information as well as its consequences, and second, by analyzing the incentives of a firm to commit not to manipulate in order to foster CSR. Section 5 endogenizes the number of firms that may be CSR, and discusses the impact of market transparency and intensity of competition on CSR. Finally, section 6 concludes.

\section{The Benchmark Model}

The model consists of a perfect competitive market in which firms sell an homogeneous good. One firm among all may differentiate from the others by attaching a credence attribute to this

good. We consider that this firm may choose to produce with a cleaner (and more expensive) technology than the rest. In the economy there is a continuum of consumers who derive a warm glow utility from consuming the good produced with the clean technology. The technology used is private information of the firm, while all consumers (and the firm itself) receive the same noisy signal regarding the type of technology used by the firm. 


\subsection{Firms and Technologies}

Competitive firms do not make profits, and the market price and the marginal cost of the homogenous good (produced with the dirty technology) are normalized to zero. One firm (henceforth, the firm) may differentiate in the market by attaching a credence attribute to the good it sells. We model this by allowing the firm to choose a clean technology rather than the dirty technology with which the rest of the firms produce. The firm, thus, may choose with which technology $t$ to produce, whether to produce the good with a clean technology $(C)$ or with the dirty and standard technology $(D)$, i.e. $t \in\{C, D\}$. The clean technology entails a fixed cost $F \geq 0$, whereas the dirty technology entails no fixed cost. In either case, the marginal cost of production is 0 .

The firm that can differentiate may be one of three different types, depending on the size of the fixed cost in which it incurs in case it uses the clean technology. ${ }^{7}$ With ex ante probability $\frac{1-\theta}{2}$ the firm has a fixed cost of $F \rightarrow \infty$ of choosing the clean technology. As a consequence, independently of market conditions, this type of firm will never choose the clean technology. With probability $\frac{1-\theta}{2}$, for the firm choosing the clean technology has a fixed cost of $F=0$. This type of firm will always choose the clean technology. Finally, with a probability $\theta$ the firm can use the clean technology with a fixed cost of $\widehat{F}$, with $0<\widehat{F}<\infty$. This firm, as we analyze below, will be "strategic" regarding its decision on which technology to use, and will be the focus of our analysis. ${ }^{8}$ The firm learns its type before the choice of the technology, and consumers do not observe the type of the firm. ${ }^{9}$

\footnotetext{
${ }^{7}$ In appendix B we also analyze the benchmark model with a continuous of types.

${ }^{8}$ An alternative way to specify three different types of firms would be to relate them to managerial disutility from using a dirty technology (analogously to Elfenbeim et al., 2014, consideration of a seller's disutility from opportunistic behaviour). Some (altruist) managers would not be willing to use a dirty technology in any case, other (non-atruist managers) would not incur in any disutility from adopting the dirty technology, and (a bit altruist) strategic managerial types would make their choice regarding the technology depending both on their disutility from adopting the dirty technology and on market incentives.

${ }^{9}$ In terms of modeling our framework is similar to Diamond (1989). The symmetry of the non strategic types is assumed for saving notation and plays no role in the results.
} 


\subsection{Consumers}

There is a mass of unit 1 of consumers with utility

$$
u=v+\alpha g-p
$$

where $v$ is the valuation of the standard good, and $g \in\{0, G\}$ is a consumer's valuation of the credence attribute attached to the good. Thus, $g=G$ in case the the firm uses the clean technology, and 0 if the good consumed is produced by the firm using the dirty technology. Let $\alpha$ represent the type of the consumer with regard to his/her degree of consciousness; more specifically, $\alpha$ determines the warm-glow derived by the consumer from consuming the good with the credence attribute attached, such as a clean environment or no child labor (Andreoni, 1989). Furthermore, we assume that $\alpha$ is distributed over the interval $[0,1]$ with a distribution function

$H(\cdot)$, and that the reliability function of the distribution, i.e $\overline{H(\cdot)}=1-H(\cdot)$, is logconcave. Finally, $p$ is the price paid by the consumer.

\subsection{Signals and Information}

The technology effectively used by the firm is not observable by the consumers. However, consumers (and the firm itself) receive the same public signal concerning the technology used by the firm, $s$, where $s \in\left\{s_{C}, s_{D}\right\}$. The realization of the public signal depends on the technology that the firm is using:

$$
\begin{aligned}
& \operatorname{Pr}\left(s_{C} \mid C\right)=1, \\
& \operatorname{Pr}\left(s_{D} \mid C\right)=0, \\
& \operatorname{Pr}\left(s_{C} \mid D\right)=1-\gamma \\
& \operatorname{Pr}\left(s_{D} \mid D\right)=\gamma,
\end{aligned}
$$

where $\gamma \in[0,1]$. That is, if the firm uses the clean technology, the signal will be $s_{C}$ with certainty. However, if the firm uses the dirty technology there is some noise and thus consumers 
may receive either signal realization. ${ }^{10}$ Notice that $\gamma$ represents the accuracy of the signal, with a higher $\gamma$ implying a more informative signal. More specifically, notice that with $\gamma=0$ the signal is non-informative whatsoever since consumers never receive signal $s_{D} \cdot{ }^{11}$

\subsection{The Market Game}

The timing of the game is as follows.

1. Nature chooses the type of firm, namely, the level of the fixed cost $F$ of the clean technology.

2. The firm chooses the technology with which it is going to produce, $t \in\{C, D\}$. The rest of the firms produce and sell the standard and dirty good (at zero price and cost).

3. Nature chooses the signal realization $s \in\left\{s_{C}, s_{D}\right\}$ according to the information structure $\operatorname{Pr}(s \mid T)$. Consumers and the firm observe the realization of the signal.

4. The firm sets its price $p$.

5. Each consumer decides whether to buy or not from the firm. The alternative is to buy the standard dirty good from the competitive fringe (at zero price).

\section{Profits are realized.}

\footnotetext{
${ }^{10}$ We can provide a rationale for this information structure based on news. Consider that the ratio between good and bad news about the firm determines the probability of signal realization, that is, $P\left(s_{C}\right)=\frac{N_{G}}{N_{B}+N_{G}}$ $\left(P\left(s_{D}\right)=\frac{N_{B}}{N_{B}+N_{G}}\right)$, where $N_{G}\left(N_{B}\right)$ are good (bad) news. News are produced by the firm, likely to provide only good news, and other private actors (such as NGOs, the media, etc.), in which case it is natural to assume that are either biased in favor of the firm (for example due to advertisement), or committed to provide truthful information (such as NGOs). Under such behavior $\operatorname{Pr}\left(s_{C} \mid C\right)=1$, since all agents will provide good news when the technology is the clean one, and $\operatorname{Pr}\left(s_{C} \mid D\right)=1-\gamma$ (there is some noise) because there is a conflict between neutral and biased actors, and hence there might be good and bad news.

${ }^{11}$ This information structure simplifies the derivation of the results since a dirty signal realization is fully informative. Introducing noise when the clean technology is chosen (and making the dirty signal less informative) would not change the results as long as we could order the signals according to their informativeness (e.g. $\left.\operatorname{Pr}\left(s_{D} \mid D\right)=\operatorname{Pr}\left(s_{C} \mid C\right)=\frac{1+\gamma}{2}\right)$.
} 


\section{The Market Equilibrium}

\subsection{Demand}

As usual, we solve the game backwards and, thus, start determining demand which depends on the marginal consumer $\bar{\alpha}$ that is indifferent between buying the good to the firm or buying the standard good from the competitive fringe (at zero price). Namely:

$$
v+\bar{\alpha} \cdot \operatorname{Pr}(C \mid s) G-p=v
$$

Then,

$$
\bar{\alpha}=\frac{p}{\operatorname{Pr}(C \mid s) G}
$$

Thus, those consumers with $\alpha \geq \bar{\alpha}$ will buy the "differentiated" good from the firm, while those with $\alpha<\bar{\alpha}$ will buy the standard good. As a consequence, and given the distribution function of $\alpha$ over $[0,1]$, the demand faced by the firm is $1-H\left(\frac{p}{\operatorname{Pr}(C \mid s) G}\right)$.

We see that demand depends on the signal received by the consumer and the posterior probability that the technology chosen by the firm is the clean one. We analyze this further below.

\subsection{Firm's Profits}

The profit of the firm (gross of fixed cost, if any) is demand times price, namely,

$$
\pi(p, s)=\left[1-H\left(\frac{p}{\operatorname{Pr}(C \mid s) G}\right)\right] \cdot p
$$

Given this profit function, and given the signal received by all consumers, which is the price set by the firm, and its posterior profits? We answer this question in Lemma 1 next, where we see that the price (and profits) of the firm depends on the public signal realization:

LEMma 1 The price set by the firm is $p^{*}(s)=\operatorname{Pr}(C \mid s) G \alpha^{*}$, whereas firm's profits (gross of fixed costs, if any) are then $\pi^{*}(s)=\left[1-H\left(\alpha^{*}\right)\right] \operatorname{Pr}(C \mid s) G \alpha^{*}$, with $\alpha^{*}=\frac{\left[1-H\left(\alpha^{*}\right)\right]}{h\left(\alpha^{*}\right)}$. 
All proofs are in the appendix. On the one hand, if the public signal realization is $s_{D}$, the posterior probability that the technology chosen by the firm is the clean one is zero. As a consequence, and since all firms are then homogeneous, the price then set by the firm is 0, i.e., the willingness that the consumer has to pay for the product when it believes that it is produced using the dirty technology (no credence attribute attached). In such a case, the firm's profits are 0.

On the other hand, if the public signal realization is $s_{C}$, then they have a positive willingness to pay for the product and the price will no be longer 0 . The optimal price (characterized in Lemma 1) is linear in the conditional probability that the clean technology has been used. As we will show in the next section, this conditional probability will be increasing in the accuracy of the signal. Given this optimal price, the more conscious consumers will buy from the firm, and the others will buy from the (rest of the) market. ${ }^{12}$ It turns out that the marginal consumer (and consequently the demand) is independent of the accuracy of the signal $\gamma$, and only depends on the distribution of the consumer "consciousness" parameter, $H(\cdot) .{ }^{13}$ Firm's profit (gross of the fixed cost) are linear both in the equilibrium price and in the conditional probability that the clean technology has been used, $\pi^{*}(s)=\Pi \operatorname{Pr}(C \mid s)$, where $\Pi=\left[1-H\left(\alpha^{*}\right)\right] G \alpha^{*}$. We can interpret $\Pi$ as the profits of the firm producing with a clean technology under perfect information; namely, the market share of the CSR good, $\left[1-H\left(\alpha^{*}\right)\right]$, multiplied by the willingness to pay of the marginal consumer, $G \alpha^{*}$.

\footnotetext{
${ }^{12}$ We can interpret Lemma 1 as firms observing consumers' public signal realization (perceptions) and tayloring prices to them. But notice that, even if firms did not observe or had imperfect information regarding the realization of $s$, the same equilibrium would arise. This is because the dirty signal is fully informative. Then, a firm with a dirty technology and uncertain of the signal obtained by consumers would set the same price than a firm with a clean technology. This is so since if the signal turns out to be the bad one, the firm will obtain zero profits no matter the price set. Market equilibrium would be more difficult to characterize for alternative information structures, but it should deliver that a firm with a better perception from consumers would obtain higher profits, which is the only requirement that we need for our results.

${ }^{13}$ To better understand the intuition of this result, we can rewrite the firm's objective function using the marginal consumer. We do so with a simple manipulation of the objective function, $\pi(p, s)=$ $\operatorname{Pr}(C \mid s) G\left[1-H\left(\frac{p}{\operatorname{Pr}(C \mid s) G}\right)\right] \cdot \frac{p}{\operatorname{Pr}(C \mid s) G}$, and a change of variable, $\bar{\alpha}=\frac{p}{\operatorname{Pr}(C \mid s) G}$, obtaining: $\pi(\bar{\alpha}, s)=$ $\operatorname{Pr}(C \mid s) G[1-H(\bar{\alpha})] \cdot \bar{\alpha}$. Then, the solution of the firm's problem in terms of the optimal marginal consumer, $\alpha^{*} \in \arg \max \pi(\bar{\alpha}, s)$, coincides (and is independent of $\operatorname{Pr}(C \mid s)$ ) with the solution of a standard optimal take-it or leave it offer, $v^{*} \in \arg \max [1-H(v)] \cdot v$, when the valuations are distributed according to $H(\cdot)$.
} 


\subsection{The Perfect Bayesian Equilibrium}

Given this above, which will be the technology chosen by the firm in equilibrium? Or, in other words, is the firm going to invest in the clean technology? Since such a choice is private information of the firm, consumers are going to have beliefs on it based on the signal received. Hence, solving the game requires solving for the perfect Bayesian equilibrium. As defined in Fudenberg and Tirole (1991), a perfect Bayesian equilibrium (PBE) is a set of strategies and beliefs such that, at any stage of the game, strategies are optimal given the beliefs, and the beliefs are obtained from equilibrium strategies and observed actions using Bayes rule. Note the link between strategies and beliefs: the beliefs are consistent with the strategies, which are optimal given the beliefs.

Clearly, the choice of technology depends on the actual type of the firm. In any case, the type with $F \rightarrow \infty$ will always choose the dirty technology while the type with $F=0$ will always choose the clean technology. We then have left to discuss what the strategic type with $0<\widehat{F}<\infty$ is going to do. Our analysis will focus on the relevant case in which $\Pi$ is larger than the fixed cost of the clean technology, that is, $\widehat{F}<\Pi$; in other words, it would be optimal for the firm to produce with a clean technology under perfect information. ${ }^{14}$ As it will be clear from the analysis below, if this condition is not met, in equilibrium strategic types will always produce with a dirty technology. We focus on pure strategies equilibrium, and we (need to) study when the strategic type is going to choose the clean technology (the socially responsible CSR equilibrium) and when it is going to choose the dirty technology (the not socially responsible NCSR equilibrium).

\subsubsection{The Corporate Socially Responsible (CSR) Equilibrium We denote as corporate} socially responsible (CSR) the equilibrium in which the strategic type firm chooses the clean technology. In equilibrium it must be that priors and beliefs are consistent with strategies. Then,

\footnotetext{
${ }^{14}$ This is a sufficent condition to ensure that producing with the clean technology is efficient under perfect information, since $W=\int_{\alpha^{*}}^{1} G x h(x) d x>\Pi=\int_{\alpha^{*}}^{1} G \alpha^{*} h(x) d x$.
} 
in such a case (and since the $F=0$ type by assumption also chooses the clean technology), priors (beliefs of consumers) are that the clean technology is chosen with probability $\frac{1-\theta}{2}+\theta=\frac{1+\theta}{2}$, and the dirty technology is chosen with probability $\frac{1-\theta}{2}$.

For the firm to be optimal to choose the clean technology over the dirty one, it must be that the expected profits (before the realization of the public signal) when choosing the clean technology are larger than the profits using the dirty technology, i.e.

$$
\pi(t=C) \geq \pi(t=D) .
$$

Let $\pi_{C S R}^{*}(s) \equiv \Pi \operatorname{Pr}(C \mid s)$ be the firm's profits in the case in which consumers anticipate that the strategic type chooses the clean technology (whereas as $\pi_{N C S R}^{*}$ will stand for the case in which consumers believe that the strategic type has chosen the dirty technology) and the realization of the public signal on the technology chosen by the firm is $s$.

Using bayes rule, we obtain $\pi_{C S R}^{*}\left(s_{D}\right)=0$ and $\pi_{C S R}^{*}\left(s_{C}\right)=\frac{\Pi(1+\theta)}{2-\gamma(1-\theta)}$. This profit function reflects the consumers' willingness to pay for the good. This willingness to pay is 0 if the realization of the signal is $s_{D}$ since in this case consumers learn that the technology was the dirty one with certainty. When the realization of the signal is $s_{C}$, then the willingness to pay is increasing on the accuracy of the signal $\gamma$.

The expected profits are

$$
\begin{aligned}
\pi(t=C) & =\operatorname{Pr}\left(s_{C} \mid C\right) \pi_{C S R}^{*}\left(s_{C}\right)+\operatorname{Pr}\left(s_{D} \mid C\right) \pi_{C S R}^{*}\left(s_{D}\right)-\widehat{F} \\
& =\pi_{C S R}^{*}\left(s_{C}\right)-\widehat{F}
\end{aligned}
$$

since $\operatorname{Pr}\left(s_{C} \mid C\right)=1$ and $\operatorname{Pr}\left(s_{D} \mid C\right)=0$. On the other hand,

$$
\begin{aligned}
\pi(t=D) & =\operatorname{Pr}\left(s_{C} \mid D\right) \pi_{C S R}^{*}\left(s_{C}\right)+\operatorname{Pr}\left(s_{D} \mid D\right) \pi_{C S R}^{*}\left(s_{D}\right) \\
& =(1-\gamma) \pi_{C S R}^{*}\left(s_{C}\right)
\end{aligned}
$$

because $\operatorname{Pr}\left(s_{C} \mid D\right)=(1-\gamma)$ and $\pi_{C S R}^{*}\left(s_{D}\right)=0$. Then, the incentive compatibility condition (4) over expected profits becomes

$$
\pi_{C S R}^{*}\left(s_{C}\right)-\widehat{F} \geq(1-\gamma) \pi_{C S R}^{*}\left(s_{C}\right),
$$




$$
\gamma \pi_{C S R}^{*}\left(s_{C}\right) \geq \widehat{F}
$$

Plugging in the expression of the profits, we obtain the necessary condition for the existence of a CSR equilibrium

$$
\gamma \pi_{C S R}^{*}\left(s_{C}\right)=\frac{\gamma(1+\theta) \Pi}{2-\gamma(1-\theta)} \geq \widehat{F},
$$

where recall that $\gamma \in[0,1]$. Notice that a necessary condition for the existence of a socially responsible equilibrium is that the fixed cost $\widehat{F}$ is smaller than $\Pi$.

\subsubsection{The Not Corporate Socially Responsible (NCSR) Equilibrium The analysis of} the NCSR equilibrium is analogous to the CSR equilibrium. Suppose now that the strategic type firm chooses the dirty technology. Then, in such a case, priors (beliefs by consumers) that a firm chooses the clean technology are $\frac{1-\theta}{2}$, whereas that a firm chooses the dirty technology are $\frac{1-\theta}{2}+\theta=\frac{1+\theta}{2}$. As we specified above, for notational purposes, let $\pi_{N C S R}^{*}\left(s_{C}\right)=\Pi \operatorname{Pr}\left(C \mid s_{C}\right)$ be the profit of the firm (gross of fixed costs) when the signal is good $\left(s_{C}\right)$ and the strategic type firm has chosen the dirty technology. Using the bayes rule, we obtain $\pi_{N C S R}^{*}\left(s_{C}\right)=\frac{(1-\theta) \Pi}{2-\gamma(1+\theta)}$. These profits are linked to the positive willingness to pay of consumers that is increasing in the accuracy of the signal. As in the previous case, when the realization of the public signal is bad the profits are zero, i.e. $\pi_{N C S R}^{*}\left(s_{D}\right)=0$. Finally, the necessary condition for the strategic type to choose the dirty technology is that

$$
\pi(t=D) \geq \pi(t=C) .
$$

For the same arguments than above, the incentive compatibility condition (5) can be written as follows

$$
\begin{aligned}
(1-\gamma) \pi_{N C S R}^{*}\left(s_{C}\right) & \geq \pi_{N C S R}^{*}\left(s_{C}\right)-\widehat{F} \\
\gamma \pi_{N C S R}^{*}\left(s_{C}\right) & \leq \widehat{F}
\end{aligned}
$$

Plugging in the expression of the profits, we obtain the necessary condition for the NCSR equilibrium

$$
\gamma \pi_{N C S R}^{*}\left(s_{C}\right)=\frac{\gamma(1-\theta) \Pi}{2-\gamma(1+\theta)} \leq \widehat{F}
$$




\subsection{Results}

Once we have characterized the equilibrium of the game, we can analyze the impact of the accuracy of the consumers' information in the payoff of the strategic firms and in the necessary conditions for the CSR and NCSR equilibria specified above.

LEMma 2 The expected profits of the strategic firm in the CSR equilibrium (NCSR equilibrium) are increasing (decreasing) in the accuracy of the signal $\gamma$.

Lemma 2 shows that the necessary condition for the CSR equilibrium (NCSR equilibrium) is easier (more difficult) to be met when the accuracy of the signal is large.

Proposition 1 When the accuracy of information $\gamma$ is small, the NCSR equilibrium is unique and the strategic firm chooses the dirty technology, whereas when the accuracy of information is large enough, the CSR equilibrium is unique, and the strategic firm chooses the clean technology. For intermediate levels of accuracy, both strategies are part of an equilibrium.

The intuition is straightforward. Only when there is enough information regarding the action followed by the firm, consumers will be willing to pay a higher price for a good labeled as socially responsible. Given that consumers' behavior depends on the information they hold, the firms' incentives to undertaking socially responsible actions also does. ${ }^{15}$ Figure 1 illustrates the characterization of the equilibrium, plotting the gross (without fixed costs) incremental profits of choosing the clean technology, $\gamma \pi^{*}\left(s_{C}\right)$, as a function of $\gamma$. These incremental profits are higher the more valuable is the clean signal $s_{C}$. Then, $\gamma \pi_{C S R}^{*}\left(s_{C}\right)$ and $\gamma \pi_{N C S R}^{*}\left(s_{C}\right)$ are increasing in $\gamma$ and $\gamma \pi_{C S R}^{*}\left(s_{C}\right)>\gamma \pi_{N C S R}^{*}\left(s_{C}\right)$ for all $\gamma$, since consumers anticipate that the strategic

\footnotetext{
${ }^{15}$ In the accompanying working paper version of the current paper we include an appendix with a continuous types model which replaces the three types set (with $F=0, F=\widehat{F}$ and $F \rightarrow \infty$ ) by a continuous set of types (Calveras and Ganuza, 2015). In particular, we assume that the clean technology entails a fixed cost $f \in[0,1]$, where $f$ is distributed according to $G(f)$, whereas the dirty technology entails no fixed cost; specifically, we focus our analysis there on the uniform distribution, i.e. $G(f)=f$. We show that the Bayesian equilibrium of that game is characterized by a cut-off type $\widehat{f}$ such that firms invest in the clean technology if $f \leq \widehat{f}$ and not otherwise, and thus the level of CSR is described by $G(\widehat{f})$. In Calveras and Ganuza (2015) we find that $\widehat{f}$ is increasing in $\gamma$, which implies that proposition 1 also holds with continuous fixed types.
} 
types choose the clean technology, and then their prior of a clean technology is higher and $P\left(C \mid s_{C}\right)$ increases. On the one hand, the condition for the CSR equilibrium in which strategic types have incentives to choose the clean technology, $\gamma \pi_{C S R}^{*}\left(s_{C}\right) \geq \widehat{F}$, requires that $\gamma$ is high enough, i.e. $\gamma \geq \underline{\gamma}$ where $\underline{\gamma}=\frac{2 \widehat{F}}{(1+\theta) \Pi+(1-\theta) \widehat{F}}$. On the other hand, the NCSR equilibrium requires $\gamma \pi_{N C S R}^{*}\left(s_{C}\right) \leq \widehat{F}$, implying that $\gamma$ has to be low enough, i.e. $\gamma \leq \bar{\gamma}$ where $\bar{\gamma}=\frac{2 \widehat{F}}{(1-\theta) \Pi+(1+\theta) \widehat{F}}$, since in this equilibrium strategic types should not have incentives to choose the clean technology. Finally, $\gamma \pi_{C S R}^{*}\left(s_{C}\right)>\gamma \pi_{N C S R}^{*}\left(s_{C}\right)$ implies that $\bar{\gamma}>\underline{\gamma}$ and, as a consequence, there exists an interval such that if $\gamma \in[\underline{\gamma}, \bar{\gamma}]$ both conditions are met and then there is multiplicity of equilibria. ${ }^{16}$ In a nutshell, we can state that the better information there is regarding the firm's practices, the more incentives the firm has to be CSR (to choose the clean technology).

\section{[INSERT FIGURE 1]}

Now, we move to the welfare analysis of both equilibria. Total welfare is linear in the conditional probability that the clean technology has been used, in which case consumers derive utility $G$ from the credence attribute attached to the good. Namely, total welfare is $W \cdot \operatorname{Pr}(C \mid s)$ minus the investment fixed cost (if any), where $W=G \int_{\alpha^{*}}^{1} x h(x) d x$. Similarly to $\Pi$ above, we can interpret $W$ as the (gross of fixed costs) total welfare generated when the clean technology is used under perfect information. Finally, consumer surplus is the difference between total welfare and firm's profits; namely, $(W-\Pi) \operatorname{Pr}(C \mid s)$. Notice that total welfare, profits and consumer surplus all depend on the actual equilibrium of the game, whether CSR or NCSR. This is explained in the following proposition.

Proposition 2 Ex ante total welfare, profits, and consumer surplus are larger in the CSR equilibrium than in the NCSR equilibrium

This proposition shows that both the firm and consumers (and, therefore, total welfare) are better off in the CSR equilibrium than in the NCSR equilibrium. Notice that the accuracy of

\footnotetext{
${ }^{16}$ As we are assuming that $\widehat{F}<\Pi$, is easy to check as it is predicted by the analysis of figure 1 that, $\underline{\gamma}=$ $\frac{2 \widehat{F}}{(1+\theta) \Pi+(1-\theta) \widehat{F}}<\bar{\gamma}=\frac{2 \widehat{F}}{(1-\theta) \Pi+(1+\theta) \widehat{F}}<1$. If $\widehat{F}=\Pi, \underline{\gamma}=\bar{\gamma}=1$, and if $\widehat{F}>\Pi, \underline{\gamma}>\bar{\gamma}>1$. Thus, in these two latter cases, the only equilibrium is NCSR.
} 
the signals (namely, $\gamma$ ) determines whether or not the CSR equilibria may arise (as stated in proposition 1) and, thus, total welfare. When in a given equilibrium (whether CSR or NCSR), however, exante welfare measures do not depend directly on the accuracy or informativeness of the signals. Proposition 2 shows us that, given our initial assumption that producing with the clean technology is optimal (and also efficient) for the strategic types under perfect information $(W>\Pi>\widehat{F})$, welfare measures are linked to the level of CSR in the economy. Hence, welfare analysis is determined by the conditions under which the CSR and NCSR equilibria can be sustained.

We conclude this section by analyzing the impact that the level or degree of 'consciousness' in society has on the strategic choice of the firm regarding technology. We do this in the following proposition, measuring the degree of consciousness in society according to the first-order stochastic dominance. Let $\widetilde{H}(\cdot)$ be an alternative distribution of $\alpha$ such that $\widetilde{H}$ first-order stochastically dominates $H$, that is, $\widetilde{H}(\cdot) \geq H(\cdot)$ for all $\alpha \in[0,1]$.

Proposition 3 In a more 'conscious' society, i.e. $\widetilde{H}(\cdot) \geq H(\cdot)$, the CSR equilibrium can be sustained for a larger set of parameters.

Proposition 3 means that, for instance, for any given value of fixed cost of investment of the strategic type $(\widehat{F})$, then $\underline{\gamma} \geq \underline{\tilde{\gamma}}$; that is, the minimum level of informational accuracy required to sustain a CSR equilibrium is lower in a more conscious society. Analogously, for a given accuracy of the signal $\gamma$, this proposition means that $\widetilde{F} \geq \widehat{F}$; that is, the CSR equilibrium can be sustained for a larger value of fixed cost of investment in a more conscious society.

\section{Endogenous InFORMATION}

In this section we first study the incentives of the firm to manipulate the information and the impact that such manipulation has on the equilibrium and on welfare, firm's profits included. And second, we analyze the incentives that some firms might have to commit unilaterally to a higher transparency by means, for instance, of a partnership with a NGO. 


\subsection{Manipulation}

Consider the case in which the firm (by means of advertising, lobbying, etc.) can improve consumers' perception of the firm when the technology used is the dirty one. This means in our model that the firm can increase $\operatorname{Pr}\left(s_{C} \mid D\right)$, namely, it decreases the accuracy of the information available to consumers, decreasing $\gamma$ to $\gamma^{\prime}$. We assume that this manipulation process is costless. Then, the timing of the game goes as follows:

1. Nature chooses the type of firm, $F$.

2. The firm chooses the technology with which it is going to produce, $t \in\{C, D\}$. The rest of the firms produce and sell the standard good (at zero price and cost).

3. The firm either manipulates or not, $m \in\{M, N M\}$, which is private information of the firm. In case of manipulation, the firm increases $\operatorname{Pr}\left(s_{C} \mid D\right)$, from $1-\gamma$ to $1-\gamma^{\prime}$, where $\gamma^{\prime}<\gamma$.

4. Nature chooses the signal realization $s \in\left\{s_{C}, s_{D}\right\}$ according to the information structure $\operatorname{Pr}(s \mid t)$ with accuracy $\gamma^{\prime}$ if $m=M$ and $\gamma$ if $m=N M$. Firms and consumers observe the realization of the public signal.

5. The firm sets its price $p$.

6. Each consumer decides whether to buy or not.

7. Profits are realized.

\subsubsection{Equilibrium with manipulation Lemma 2 above shows that the expected profits} of the strategic firm decrease with accuracy of information when it is using a dirty technology, and increase when it is using the clean technology. For the same token, manipulation is going to be used only by firms using a dirty technology. If the firm uses the clean technology, it is not interested in manipulation because, by assumption, the signal will be the clean one. ${ }^{17}$ If the firm

\footnotetext{
${ }^{17}$ Even, if we would consider information structures that allow for noise when the clean technology is chosen, firms using clean technology would have incentive to increase (and not decrease) the accuracy of the signal.
} 
uses the dirty technology, manipulating increases firm's profits because taking in equilibrium the value of the signals as given, manipulation increases the probability that the signal is good, $s_{C}$. In short, then, manipulation makes it relatively more attractive to invest in the dirty technology, implying that it is more difficult to find an equilibrium in which the strategic firm chooses the clean technology. The next proposition states this result.

Proposition 4 The possibility of manipulation reduces the set of parameters for which a CSR equilibrium can be sustained.

In particular, if the fixed cost of the strategic type $(\widehat{F})$ lies over the interval $\left[\frac{\gamma^{\prime}(1+s) \Pi}{2-\gamma^{\prime}(1-s)}, \frac{\gamma(1+s) \Pi}{2-\gamma(1-s)}\right]$, the possibility of manipulation eliminates the CSR equilibrium. The intuition goes as follows. When manipulation is costless, the non strategic type with $F=+\infty$ will always manipulate. This worsens the value of the good signal and consequently makes less attractive the clean technology. Moreover, as we said above, the possibility of manipulation makes it more profitable to the strategic type to deviate from the CSR equilibrium since it increases the probability that the signal is $s_{C}$ without incurring in the fixed cost. Both effects thus lead to make it more difficult that necessary conditions for the CSR equilibrium are met.

From proposition 2 above we know that manipulation (reducing $\gamma$ ) reduces exante expected total welfare (including both consumer surplus and firm's profits), in the sense that it reduces the set of parameters for which a CSR equilibrium can be sustained. This result refers to an exante welfare analysis before types are realized. It is thus interesting to know what types of firms benefit from the possibility of manipulation. The non strategic type with $F=0$ and the strategic type with $\widehat{F}$ such that they choose a clean technology independently of the possibility to manipulate decrease their profits because the value of the good signal is reduced. The non strategic type with $F \rightarrow \infty$ and the strategic type with $\widehat{F}$ such that it chooses a dirty technology independently of the possibility to manipulate, increase their profits since increasing the probability a good signal through manipulation overcomes the loss of value of the good signal.

It is specially interesting the case in which the possibility of manipulation makes unfeasible the CSR equilibrium when it was possible without such manipulation. In such a situation, there 
are strategic types that choose a clean technology when manipulation is not possible, but when this possibility exists they then choose a dirty technology and reduce the accuracy to $\gamma^{\prime}$ afterwards. This, however, does not mean that these types are better off with manipulation; in fact, next Lemma states that some of these strategic types are worse off because of the possibility to manipulate.

LEMMA 3 The possibility of manipulation may lead a strategic firm (that, absent such possibility, would choose the clean technology) to choose the dirty technology and then manipulate. Furthermore, some of these firms may show a reduction in their profits due to such manipulation.

This result is driven by the fact that manipulation decreases the value of a good signal, $s_{C}$, and the switching firms considered in the Lemma obtain lower profits with the clean technology with the possibility of manipulation than without it. In the proof of Lemma 3 it is shown that, although using the dirty technology and manipulating is more profitable for these switching firms than using the clean technology with a devaluated good signal, for a subset of them these profits with manipulation are lower than using a clean technology in a setup without manipulation possibility with a valuable clean signal.

We have taken as given the outcome of the manipulation process that leads accuracy from $\gamma$ to $\gamma^{\prime}$ and we have also assumed that this process was costless. In practice, however, manipulation may involve a cost, and $\gamma^{\prime}$ should be the solution to an optimization problem. In particular, as the cost of manipulation is likely to increase with the stringency of transparency regulatory measures, it is also likely then that more stringent transparency regulatory policies reduce the net benefits of manipulation, reducing the distance between $\gamma$ and $\gamma^{\prime} \cdot{ }^{18}$ As a consequence, a more stringent transparency regulation that reduces the distance between $\gamma$ and $\gamma^{\prime}$ enlarges the set of parameters for which a CSR equilibrium can be sustained. In other words, making transparency

\footnotetext{
${ }^{18}$ Consider, for example, that the effective reduction to $\gamma^{\prime}$ from $\gamma$ is in fact the solution of the following problem, $\gamma^{\prime} \in \arg \max \pi\left(D ; \gamma_{M}\right)-C\left(\gamma-\gamma_{M}\right)$, where $\pi\left(D ; \gamma_{M}\right)$ are the profits of using a dirty technology when the accuracy of the signal is $\gamma_{M}$ and $C\left(\gamma-\gamma_{M}\right)$ is the cost of manipulation that may include lobbying, advertisements, and also penalties imposed by the regulator. These penalties are likely to be larger the higher the manipulation $\gamma-\gamma_{M}$. As a consequence, a tougher regulation that involves, for example, higher fines and a higher marginal cost of manipulation, may lead to a higher $\gamma^{\prime}$ (lower level of manipulation).
} 
regulation more strict increases the costs of manipulating the information making it less attractive for strategic types.

\subsection{Commitment through external agents}

The previous results imply that some firms may favor an increase in the transparency regarding their business practices (the choice of technology in our model). A higher transparency might be achieved through different institutional settings (e.g., through regulatory policies). In this section, we focus on the incentives that some firms might have to commit unilaterally to a higher transparency; namely, to commit not to manipulate the information that will be available to consumers regarding the technology choice of the firm. As we discuss in the following subsection, an example of such a business strategy can be found in the many partnerships between firms and NGOs whose logic lies in the role of the NGO as a an independent and reputable certifier of some of the firm's business practices.

To undertake such an analysis, consider the previous model with an additional period in which firms may choose to commit to not manipulate by incurring in a cost $c$ (consider for example a partnership or auditing fee). It is natural to assume that this commitment is visible to consumers and that they update their valuation of the product using the commitment decision as well as the realization of the signal. Then, the timing of this new signaling game goes as follows:

1. Nature chooses the type of firm, $F$.

2. The firm decides whether or not to commit to not manipulate, $d \in\{C o, N C\}$. This commitment decision is visible and entails a cost $c \geq 0$.

3. The firm chooses the technology with which it is going to produce, $t \in\{C, D\}$. The rest of the firms produce and sell the standard dirty good (at zero price and cost).

4. If the firm has not committed in stage 2 , it decides whether to manipulate or not, $m \in$ $\{M, N M\}$, which is private information of the firm. In case of manipulation, the firm 
increases $\operatorname{Pr}\left(s_{C} \mid D\right)$, from $1-\gamma$ to $1-\gamma^{\prime}$, where $\gamma^{\prime}<\gamma$.

5. Nature chooses the signal $s \in\left\{s_{C}, s_{D}\right\}$ on the technology used by the firm according to the information structure determined by $\operatorname{Pr}\left(s_{C} \mid t\right)$. Firms and consumers observe the realization of the public signal. Consumers update their beliefs using the signal realization and the firm's commitment decision, $P(C \mid s, d)$.

6. The firm sets its price $p$.

7. Each consumer decides whether to buy or not.

8. Profits are realized.

\subsection{Equilibrium with commitment and manipulation}

The perfect Bayesian equilibrium of the game specifies the optimal strategy for every type $\left(d_{F}^{*}, t_{F}^{*}, m_{F}^{*}\right)$ and a system of consumer's beliefs that, simplifying notation, we summarize in $P(C \mid s, d)$. Consumers observe the firm's decision over commitment, and update their beliefs over the type of the firm. They combine this information with the realization of the signal for obtaining the posterior $P(C \mid s, d)$. Since there might be a conflict between the realization of the signal and extreme values of the types' beliefs, we assume that independently of the beliefs, a bad signal realization always reveals the type of technology, namely $P\left(C \mid s_{D}, d\right)=0$.

As it is common in signaling games, there is a multiplicity of perfect Bayesian equilibria that depend on the set of parameters as well as on the belief system. Rather than fully characterizing all equilibria, we address the question of whether or not commitment may be a device for sustaining the CSR equilibria. In order to do that, we focus on the separating equilibrium in which the strategic type with $\widehat{F}>0$ and the non-strategic type $F=0$ choose to commit, and the type $F \rightarrow \infty$ chooses not to, and the strategic type chooses to invest in the clean technology. In such an equilibrium, when consumers observe no commitment they correctly anticipate that they are facing a type $F \rightarrow \infty$ and, independently of the realization of the signal, they set a posterior 
$P(C \mid s, N C)=0$. Given this belief system, the profits of type $F \rightarrow \infty$ are always zero. In this equilibrium, the relevant asymmetric information vanishes (there is still uncertainty over the type of the firm, with $\widehat{F}>0$ or with $F=0$ ), since when consumers observe commitment and receive the clean signal, they learn with certainty that the technology is clean. Hence, the profits of the strategic type are $\Pi-\widehat{F}-c$. Next proposition establishes conditions for this separating equilibrium to exist.

Proposition 5 Consider the separating equilibrium in which the strategic type with $\widehat{F}>0$ and the type $F=0$ choose to commit and the type $F \rightarrow \infty$ chooses not to, and the strategic type chooses to invest in the clean technology. If $\gamma \Pi>\widehat{F}$, there exists a cost of commitment $c \in((1-\gamma) \Pi, \Pi-\widehat{F})$ such that the separating equilibrium exists, which enlarges the set of parameters $(\gamma, \widehat{F})$ for which the CSR equilibrium exists.

Notice that $\gamma \Pi>\widehat{F}$ is a less demanding condition than $\gamma \pi_{C S R}\left(s_{C}\right)>\widehat{F}$, implying there exists a combination of parameters $(\gamma, \widehat{F})$ for which the CSR equilibrium fails to exist unless there is a possibility of commitment with a third party. Then, private commitment and the transparency regulation that we have considered above (that reduces the distance between $\gamma$ and $\gamma^{\prime}$ ), both reduce the social cost of information manipulation and increase the set of parameters for which a CSR equilibrium can be sustained. However, while the former regulatory instrument can only restore the initial condition of the CSR equilibrium $\left(\gamma \pi_{C S R}\left(s_{C}\right)>\widehat{F}\right)$, private commitment can go beyond it.

Welfare comparisons are ambiguous. This separating equilibrium entails an additional cost $c$ that has to be incurred by strategic types with $\widehat{F}>0$ and the types with $F=0$. Following Proposition 2, the difference in expected total welfare between the CSR and the NCSR equilibrium depends on the weight of strategic types in the economy, namely $W_{C S R}-W_{N C S R}=\theta(W-\widehat{F})>0$. Thus, if the weight of strategic types in the economy is small (low $\theta$ ), the cost $c$ of implementing the separating equilibrium does not compensate for the expected gain of welfare of moving to a CSR equilibrium from a NCSR equilibrium. On the contrary, if $\theta$ is sufficiently large, the welfare 
gains can compensate for any implementing cost $c \in((1-\gamma) \Pi, \Pi-\widehat{F})$. Similar analysis can be done regarding firm's profits.

Another condition of the equilibrium is that the cost of commitment is intermediate, neither too large nor too small. On the one hand, it is intuitive that if $c$ is very large, then commitment becomes a non profitable strategy. On the other hand, if $c$ is too low, mimicking becomes easy for types that do not plan to invest in the clean technology, destroying the incentives to commit. In fact, in the Appendix $\mathrm{C}$ we show that if $c=0$, any separating equilibrium fails to exist and only a pooling equilibrium arises. We also show then that only when $\gamma-\gamma^{\prime}$ is large enough, the only equilibrium in pure strategies that satisfies the intuitive criterium is the pooling equilibrium in which all types of firms follow a commitment strategy. Then, if $c=0$, transparency regulation that reduces the distance between $\gamma$ and $\gamma^{\prime}$ is a strategic substitute of self-commitment to transparency by firms.

\subsection{Partnerships between firms and NGOs}

The previous analysis shows that, under some circumstances, firms may have incentives to commit not to be able to manipulate the information available to consumers with regards to the technology used in production. In other words, to increase the transparency with regards to its choice of technology. It is our opinion that such result lies behind the rationale for many of the partnerships between a firm (or a group of firms) and an NGO (or a group of them) that we observe in many industries. ${ }^{19}$ According to Yaziji (2004), one of the strengths that NGOs have (as apposed to corporations) is 'legitimacy'20. As Yaziji (2004) explains, and according to a poll conducted by the Edelman public relations firm, both Americans and Europeans said they found NGO spokespeople more credible than either a company's CEO or Public Relations representative. Some fraction of the public, specially in Europe, sees NGOs as dedicated first

\footnotetext{
${ }^{19}$ The rationales behind such partnerships may vary and are not confined to the rationale presented in this paper. For instance, Brugman and Prahalad (2007) discuss such alliances between a firm and an NGO for the purpose of developing some entrepreneurship and business model in the developing world. Such a partnership allows firms and NGOs to share some knowledge and capabilities that are specific to each one.

${ }^{20}$ The other three are awareness of social forces, distinct networks and specialized technical expertise.
} 
and foremost to serving an aspect of the general social welfare. This is what gives credibility to their positions regarding social issues as, e.g., are the environmental ones. Such 'legitimacy' is precisely the reason why in our framework NGOs can be used by firms as a way to commit to the public (consumers) to a certain course of action and can increase the transparency of their actions. Furthermore, Yaziji (2004) also stresses that partnering with NGOs, and advertising it, can draw stricter scrutiny form the public, the press, the regulators, and so on than your company formerly received. Notice that such effect of partnering with an NGO is analogous to increasing transparency in our framework, making it more difficult to manipulate the information.

Examples of such partnerships between a firm and an NGO abound. In the garment industry, for instance, the firm GAP, in its aim to try to ensure a proper treatment of workers in the factories that are part of its supply chain, provides two independent evaluations of GAP's factory inspection program by the NGOs Social Accountability International and Verite. In another example, the multinational firm Starbucks has developed a partnership with an NGO, environmental group Conservation International, with the aim of increasing transparency in their operations and assuring that the operations were done under sound conditions.

\section{Competition in CSR}

In this section we extend our model to a competition framework in order to study the effect of information accuracy when the number of CSR firms is endogenized. As in the benchmark model, there is an homogenous good which is produced competitively with the dirty standard technology. We now consider that any firm can position itself in the market segment for CSR goods by investing an exogenous amount $k$ (this entry cost $k$ might be interpreted, for instance, as the cost

of advertisement). Only after positioning itself in the CSR segment, a firm learns its type (its fixed cost of investing in the clean technology), and then decides whether to invest or not. To keep the model tractable, we ignore the moral hazard problem present in the benchmark model and we 
consider only the existence of non strategic types. ${ }^{21}$ Thus, with probability $\widetilde{\theta}$ a firm's type is $F=0$, while with a probability $1-\widetilde{\theta}$ its type is $F \rightarrow \infty$. Firms' types are independently and identically distributed. All 'active' firms (those that incurred cost $k$ and entered and positioned themselves in the CSR segment) then compete among themselves and with all other firms present in the standard and dirty good market. As it will be detailed below, competition among 'active' firms is assumed to take one of three possible forms: (i) price competition à la Bertrand, (ii) collusive price competition, and (iii) imperfect market competition, an intermediate level of competition. The demand side of the model (consumer preferences, etc.) and the information structure (signals, etc.) are assumed identical as those in our benchmark model.

The timing of this model with firm competition in CSR is thus as follows:

1. Any firm decides whether or not to enter into the 'active' market by incurring an entry cost $k$. If a firm does not incur such a cost, it continues to produce the 'dirty' standard good (at a zero marginal cost, price equal zero, and obtaining zero profits).

2. Nature chooses the type of firm, namely, the level of the fixed cost $F$ of investing in the clean technology, for each firm that entered the "active" segment. Firms' types, $F_{i}, i \in\{1,2, \ldots, n\}$ are identically and independently distributed according to the binary distribution function $\{\widetilde{\theta}, 1-\widetilde{\theta}\}$.

3. Each firm in the 'active' market (the CSR segment) chooses the technology with which it is going to produce, $t \in\{C, D\}$. Notice that since in the present analysis there are only two types of fixed costs, $F=0$ and $F \rightarrow \infty$, those active firms with $F=0$ will always invest and sell a good produced with the clean technology, whereas those firms with $F \rightarrow \infty$ will never do so.

\footnotetext{
${ }^{21}$ This model of competition is devised for endogenizing the number of firms. In the accompanying working paper Calveras and Ganuza (2015) we analyze an alternative competitive model that is more related to the previous monopoly model. In particular, this alternative model takes the number of active firms in the CSR segment as given (without an entry stage) and includes strategic types. This model has a large multiplicity of equilibria, but focusing on the symmetric pure strategy equilibria we show that the main message of the monopoly case is robust to the introduction of competition: for a given number of firms, the better information there is regarding the firm's CSR practices, the more incentives firms have to invest in the clean technology.
} 
4. Nature chooses a (potentially different) signal $s \in\left\{s_{C}, s_{D}\right\}$ for each firm on the technology used (according to information structure). All consumers receive the same signal for each firm, and all firms also observe all signals.

5. Each firm sets its price $p$.

6. Each consumer decides whether to buy or not from one of the 'active' firms and, if so, from which one. The alternative is to buy the standard good from the competitive fringe (at zero price and deriving zero utility).

7. Profits for all firms are realized.

As usual, the game is solved backwards. Demand is determined precisely as before, where consumers choose between buying a CSR good or a standard dirty one. Consumers receive signals, $s \in\left\{s_{C}, s_{D}\right\}$, over the investments decisions of the $n$ active firms. Given the information structure and that firms' types are independently and identically distributed, consumer's beliefs on the technology chosen by a firm given the signal received are (remember now there are only two types of fixed costs): $\operatorname{Pr}\left(C \mid s_{D}\right)=0$ and $\operatorname{Pr}\left(C \mid s_{C}\right)=\frac{\operatorname{Pr}\left(s_{C} \mid C\right) \widetilde{\theta}}{\operatorname{Pr}\left(s_{C} \mid C\right) \widetilde{\theta}+\operatorname{Pr}\left(s_{C} \mid D\right)(1-\widetilde{\theta})}=\frac{\widetilde{\theta}}{\widetilde{\theta}+(1-\gamma)(1-\widetilde{\theta})}$.

\subsection{Market competition: prices}

It is necessary to determine the way in which all 'active' firms that paid the sunk cost $k$ (positioned in the CSR market segment) compete among them. Notice that given our information structures, dirty signals $s_{D}$ are fully informative. Then, when consumers receive a dirty signal $s_{D}$ from one firm, their willingness to pay for that firm's product is zero and, consistently with the previous section, firm's price and profit equal zero. It is thus left to determine pricing by those firms that are positively perceived by consumers by having generated a clean signal $s_{C}$. To simplify the analysis, we consider three market structures: (i) Bertrand price competition, (ii) price collusion at the monopoly price, and (iii) imperfect competition. 
Bertrand price competition Assume the active firms compete in prices à la Bertrand. This implies that firms with a clean signal $s_{C}$ will compete in prices until prices equal marginal costs, namely zero; thus, whenever two or more firms yield a clean signal, prices for these firms will be zero, obtaining zero profits (minus the entry cost $k$ ). It should then be clear that the only way in which a firm obtains positive profits is the case in which its signal is the only clean signal in the market. In this case, the firm will set the monopoly price of the benchmark model.

Price collusion The other pricing scenario which we consider is the one in which all active firms with a clean signal $s_{C}$ collude in prices by agreeing to the monopoly price of the benchmark model. In this case, an 'active' firm with a clean signal will obtain positive profits determined by the monopoly profits and its market share (its demand will be the monopoly demand divided by the number of firms with a clean signal).

Imperfect competition. We consider in a reduced form an intermediate framework between the two previous ones. Assume that firms with a clean signal $s_{C}$ face a discontinuous demand: a proportion $(1-\mu)$ of their potential consumers cannot buy products of their competitors (for instance, because they cannot reach them or are not aware of them, or they are loyal consumers), while the remaining $\mu$ are able to take advantage of Bertrand price competition. We can thus interpret $\mu$ as the degree or intensity of market competition.

\subsection{Entry}

Proceeding backwards, it is left to determine entry, namely, how many firms will position into the CSR market segment by incurring in the sunk cost $k$. Notice that the entry decision is taken by a firm prior to learning its actual type, but anticipating the type of competition that will take place. Then, the entry decision depends on the gross ex-ante expected profits of entering the market, $\pi(n)$, which is a function of $n$ (the number of firms that will be present in the CSR market segment), and the type of competition. More precisely, a firm decides to position itself in 
the CSR market segment if these ex-ante gross profits $\pi(n)$ minus the entry cost $k$ are larger than zero (the profits of producing the dirty homogenous good), i.e. if $\pi(n)-k \geq 0$.

Competition à la Bertrand Consider first the scenario in which after entry firms with a clean signal $s_{C}$ will compete à la Bertrand. Market profits are going to be zero unless the firm is the only one to generate a clean signal. The probability of such an event is the probability that this firm will get a clean signal $(\widetilde{\theta}+(1-\widetilde{\theta})(1-\gamma)$, because it invested or by luck) times the probability that no other active firm will do so $\left([(1-\widetilde{\theta}) \gamma]^{n-1}\right.$, no other firm that entered gets to be of the type $F=0$, and no firm with $F \rightarrow \infty$ is lucky and generates the clean signal). Then, expected gross profits are the probability of ending up being a monopolist times the profits in such a case, namely:

$$
\pi(n)=[\widetilde{\theta}+(1-\widetilde{\theta})(1-\gamma)][(1-\widetilde{\theta}) \gamma]^{n-1} \Pi \operatorname{Pr}\left(C \mid s_{C}\right)
$$

Plugging $\operatorname{Pr}\left(C \mid s_{C}\right)=\frac{\widetilde{\theta}}{\widetilde{\theta}+(1-\gamma)(1-\widetilde{\theta})}$ into the expression and simplifying, we obtain

$$
\pi(n)=[(1-\widetilde{\theta}) \gamma]^{n-1} \Pi \widetilde{\theta}
$$

Therefore, firms enter as long as $\pi(n)-k \geq 0$, and the equilibrium number of firms $n^{*}$ in the market is given by the following expression:

$$
[(1-\widetilde{\theta}) \gamma]^{n^{*}-1} \Pi \widetilde{\theta}=k
$$

It is easy to see that the left hand side is increasing in $\gamma$ and decreasing in $n^{*}$ (since $(1-\widetilde{\theta}) \gamma<1$ ), which implies that $n^{*}$ is increasing in $\gamma$ and decreasing in $k^{22,23}$

Price collusion Consider now that, instead of competing à la Bertrand, all active firms with a clean signal collude in prices by agreeing to the monopoly price (as the one in the benchmark

\footnotetext{
${ }^{22}$ We treat $n$ as a continuous variable for simplifying the presentation. If we replace the market equilibrium condition for its discrete version, i.e $[(1-\tilde{\theta}) \gamma]^{n^{*}-1} \Pi \tilde{\theta} \geq k>[(1-\tilde{\theta}) \gamma]^{n^{*}} \Pi \widetilde{\theta}$, none of our results and intuitions change.

${ }^{23}$ An alterntive model with competition and strategic types analyzed in Calveras and Ganuza (2015) delivers a similar result. In a setting with a given number of firms and competition à la Bertrand, a market with more competition (larger $n$ ) requires better information on firms' practices for keeping their incentives to be CSR.
} 
model) and then divide the demand equally among themselves. Then, the profits of an arbitrary firm entering into the CSR market segment are determined by the probability of generating a clean signal $\widetilde{\theta}+(1-\widetilde{\theta})(1-\gamma)$ and the expected number of active firms with a clean signal with whom it will share the market at the monopoly price, namely:

$\pi(n)=[\widetilde{\theta}+(1-\widetilde{\theta})(1-\gamma)]\left[\operatorname{Pr}(X=0)+\operatorname{Pr}(X=1) \frac{1}{2}+\ldots+\operatorname{Pr}(X=n-1) \frac{1}{n-1}\right] \Pi \operatorname{Pr}\left(C \mid s_{C}\right)$, where $\operatorname{Pr}(X=x)$ is the probability of having $x$ firms out of the other $n-1$ with a clean signal. Notice that $X$ follows the binomial distribution with parameters $n-1$ and $p \equiv \widetilde{\theta}+(1-\widetilde{\theta})(1-\gamma)$, which we write $X \sim B(n-1, p)$. The probability of getting exactly $x$ successes (clean signals in $n-1$ trials) is given by the probability mass function:

$$
\operatorname{Pr}(X=x)=\left(\begin{array}{c}
n-1 \\
x
\end{array}\right) p^{x}(1-p)^{n-x-1},
$$

where $\left(\begin{array}{c}n-1 \\ x\end{array}\right)=\frac{(n-1) !}{x !(n-x-1) !}$. Plugging $\operatorname{Pr}\left(C \mid s_{C}\right)=\frac{\widetilde{\theta}}{\widetilde{\theta}+(1-\widetilde{\theta})(1-\gamma)}$ into the expression and using the definition of the binomial distribution, we can rewrite the ex-ante gross profit function as

$$
\begin{aligned}
\pi(n) & =E\left\{\frac{1}{1+B(n-1, p)}\right\} \Pi \tilde{\theta} \\
& \simeq \frac{\Pi \tilde{\theta}}{1+(n-1) p} \\
& =\frac{\Pi \widetilde{\theta}}{1+(n-1)[\widetilde{\theta}+(1-\tilde{\theta})(1-\gamma)]}
\end{aligned}
$$

where $\frac{1}{1+(n-1) p}$ is the first-order approximation of $E\left\{\frac{1}{1+B(n-1, p)}\right\}$ when we use the delta method.

As in the previous case, firms decide to enter as long as $\pi(n)-k \geq 0$, and thus the equilibrium number of firms $n^{*}$ in the market is given by the following expression:

$$
\frac{\Pi \widetilde{\theta}}{1+\left(n^{*}-1\right)[\widetilde{\theta}+(1-\widetilde{\theta})(1-\gamma)]}=k
$$

The left hand side is increasing in $\gamma$ and decreasing in $n^{*}$, which implies that $n^{*}$ is increasing in $\gamma$ and decreasing in $k$.

Imperfect competition Assume now that a firm with a clean signal $s_{C}$ has monopoly power over a proportion $(1-\mu)$ of their potential consumers, while faces Bertrand price competition for 
the remaining $\mu$ part of the demand. Following above results, a firm's gross expected profits will be determined by the probability of getting a clean signal $(\widetilde{\theta}+(1-\widetilde{\theta})(1-\gamma))$, times a convex combination of the profits of the Bertrand segment and the monopoly segment:

$$
\pi(n)=[\widetilde{\theta}+(1-\widetilde{\theta})(1-\gamma)]\left(\mu[(1-\widetilde{\theta}) \gamma]^{n-1}+1-\mu\right) \Pi \operatorname{Pr}\left(C \mid s_{C}\right)
$$

Using $\operatorname{Pr}\left(C \mid s_{C}\right)=\frac{\widetilde{\theta}}{\widetilde{\theta}+(1-\gamma)(1-\widetilde{\theta})}$ and the entry-condition, $\pi(n)-k \geq 0$, we can characterize the equilibrium number of firms $n^{*}$ in the market:

$$
\begin{aligned}
\left(\mu[(1-\tilde{\theta}) \gamma]^{n^{*}-1}+1-\mu\right) \Pi \tilde{\theta} & =k, \\
{[(1-\widetilde{\theta}) \gamma]^{n^{*}-1} } & =\frac{\frac{k}{\Pi \widetilde{\theta}}-(1-\mu)}{\mu} .
\end{aligned}
$$

For the same argument than above, $n^{*}$ is increasing in $\gamma$ and decreasing in $k$. More interestingly, we can now analyze how the degree (intensity) of competition $\mu$ affects the equilibrium number of firms in the market. The right hand side is increasing in $\mu$, which implies that the number of active firms in equilibrium is decreasing with $\mu$. A nice implication of these results is that in a market with more intense competition, a higher degree of transparency is required in order to sustain a given level of CSR (or 'green') firms.

The following proposition summarizes the role of information accuracy and intensity of market competition on CSR in a framework where the number of firms that can be CSR is endogenous:

Proposition $6 \quad$ 1. In more transparent markets (larger $\gamma$ ) a larger number of firms will be socially responsible.

2. A higher intensity of market competition (higher $\mu$ ) implies that fewer firms are socially responsible.

3. In a market with more intense competition, a higher degree of transparency is required in order to sustain a given number of CSR firms. 


\section{CONCLuding REMARKS}

The rise in the importance of the phenomena of corporate social responsibility that has taken place in the last 15 or 20 years is inextricably linked to both an increase in the "consciousness" of markets (consumers, investors, workers) with regards to social and environmental issues, as well as to an increase in the transparency of market and non-market behavior of firms. Our focus in this paper has been precisely the study of the role that informational issues play in the promotion of CSR and, more specifically, in the incentives that firms (a single firm as a monopolist, or firms in competition for 'conscious' consumers) have to invest in CSR business practices.

We assume there is a demand by consumers of a good with some CSR credence attribute (e.g., that the good is produced with a green or clean technology). Since such an attribute is not directly observable by consumers, demand and willingness to pay must depend on consumer's perception of the firm which, in turn, depends on some indirect information: in our set-up a signal that all consumers receive regarding the technology used by the firm. This signal is a reduced form modelling of the information that consumers receive about firms (e.g., through media). The first result in our paper is quite intuitive: the better the information available to consumers, the more consumers are willing to pay for a good labeled as CSR (or 'green') and, accordingly, the more incentives firms have to adopt such a mode of production. ${ }^{24}$ A higher accuracy of information available to consumers impacts positively both a monopolist CSR firm as well as competing firms in search of 'conscious' consumers. It is also true, however, that markets with a stronger degree (intensity) of competition will show a lower level of CSR (a smaller number of CSR firms in our modelling).

We acknowledge that the availability to consumers of information on the firm's practices is endogenous, namely, it is dependent on many actors' behavior. Such information is dependent not only on media behavior (the press, TV), but also other stakeholder's behavior, such as NGOs,

\footnotetext{
${ }^{24}$ In addition to numerous anecdotal evidence, Xia et al. (2008) show empirical evidence on the impact of media freedom in the adoption by firms (and the correpsonding global diffusion) of the environmental ISO 14001 certification. See also Dyck and Zingales (2002) on the responsiveness of firms towards environmental issues as a function of a higher diffusion of the press, a construct for market transparency.
} 
activist shareholders and institutional shareholders, financial analysts, and the information provided by the firm itself. Hence, we have endogenized the information available to consumers by allowing the firm to manipulate such information in a way that decreases the accuracy of the signal received. As a result of such manipulation capability, an equilibrium with socially responsible business practices becomes less likely: since consumers know that the information they have is likely to have been manipulated, they are less willing to pay a premium for the supposedly CSR product, and then a firm has less incentives to adopt the (more costly) CSR mode of production.

More surprising, though, is that some of these firms end-up worse-off because of their possibility to manipulate the information provided to consumers. This is so because such manipulation possibility destroys a CSR equilibrium in which the firm provided the good with the CSR credence attribute, and the consumer paid a premium price. As a consequence of the decrease in profits due to the manipulation possibilities, these firms (the ones that, absent the possibility to manipulate, would invest in social responsibility) would favor any measure that ties their hands and impedes them to manipulate the information; in other words, a measure that increases the transparency in the market regarding the firm's mode of production. Alternative institutional arrangements might play such role, such as, for instance, transparency regulation by the public sector (e.g., the European Union Directive 1999/94/EC which requires car makers to inform consumers on fuel economy and $\mathrm{CO} 2$ emissions of each car), or a decentralized solution to increase market transparency such as the observed partnerships between firms and NGOs (e.g., GAP and the NGO Verité; the multinational fruit company Chiquita and Rainforest Aliance, Starbucks and Conservation International, etc.). While acknowledging that such partnerships may serve several purposes, we provide a rationale behind such alliances in the way that an independent and reputable NGOs may be capable of credibly communicating consumers that the information, even though maybe still noisy, has not been manipulated by the firm. When such partnerships become available to firms, we show there exists a separating perfect Bayesian equilibrium in pure strategies in which such partnerships are formed with the purpose of firms to credibly and visibly commit in the eyes of consumers to not manipulate the information they receive. In such a way, 
transparency in the market is increased, and a socially responsible equilibrium becomes more likely. An interesting avenue for future research, one at which we already hint at the paper with some discussion, is about the comparative advantage of transparency regulation and alternative decentralized institutional arrangements in order to increase market transparency, such as, for instance, a firm-NGO partnership.

\section{A Proofs}

Proof of Lemma 1: As $\overline{H(\cdot)}=1-H(\cdot)$ is logconcave, $\pi(p, s)$ is quasiconcave on $p$ (see Bagnoli and Bergstrom, 2005) and the optimal price is given by the first order condition:

$$
-h\left(\frac{p^{*}}{\operatorname{Pr}(C \mid s) G}\right) \cdot \frac{p^{*}}{\operatorname{Pr}(C \mid s) G}+1-H\left(\frac{p^{*}}{\operatorname{Pr}(C \mid s) G}\right)=0 .
$$

Taking $\bar{\alpha}=\frac{p}{\operatorname{Pr}(C \mid s) G}$, the solution is characterized by $\alpha^{*}=\frac{\left[1-H\left(\alpha^{*}\right)\right]}{h\left(\alpha^{*}\right)}$. As $\alpha^{*}$ is a feature of the distribution $H(\cdot)$ and it is independent of $\operatorname{Pr}(C \mid s)$ and $p$, we can characterize the optimal price and firm's posterior profits as functions of $\alpha^{*}$ :

$$
\begin{aligned}
& p^{*}(s)=\operatorname{Pr}(C \mid s) G \alpha^{*}, \\
& \pi^{*}(s)=\left[1-H\left(\alpha^{*}\right)\right] \operatorname{Pr}(C \mid s) G \alpha^{*} .
\end{aligned}
$$

\section{Proof OF LEMMA 2:}

i) The expected profits of the strategic type in the CSR equilibrium are:

$$
\pi(t=C)=\pi_{C S R}^{*}\left(s_{C}\right)-\widehat{F}=\frac{(1+\theta) \Pi}{2-\gamma(1-\theta)}-\widehat{F}
$$

If we take the derivative over the accuracy of the signal $\gamma$, we obtain:

$$
\frac{d \pi(t=C)}{d \gamma}=\frac{(1-\theta)(1+\theta) \Pi}{(2-\gamma(1-\theta))^{2}}>0
$$

ii) The expected profits of the strategic type in the NCSR equilibrium are:

$$
\pi(t=D)=(1-\gamma) \pi_{N C S R}^{*}\left(s_{C}\right)=\frac{(1-\gamma)(1-\theta) \Pi}{2-\gamma(1+\theta)} .
$$


If we take the derivative over the accuracy of the signal $\gamma$, we obtain:

$$
\frac{d \pi(t=D)}{d \gamma}=\frac{-(1-\theta)(1-\theta) \Pi}{(2-\gamma(1+\theta))^{2}}<0
$$

Proof of Proposition 1: The characterization of the equilibrium depends on both conditions stated in the main text:

$$
\begin{aligned}
\gamma \pi_{C S R}^{*}\left(s_{C}\right) & =\frac{\gamma(1+\theta) \Pi}{2-\gamma(1-\theta)} \geq \widehat{F}, \\
\gamma \pi_{N C S R}^{*}\left(s_{C}\right) & =\frac{\gamma(1-\theta) \Pi}{2-\gamma(1+\theta)}<\widehat{F} .
\end{aligned}
$$

Notice that as $\gamma \in[0,1], \pi_{C S R}^{*}\left(s_{C}\right)-\pi_{N C S R}^{*}\left(s_{C}\right)=\frac{4 \theta(1-\gamma) \Pi}{(2-\gamma(1-\theta))(2-\gamma(1+\theta))} \geq 0$. In particular, $\pi_{C S R}^{*}\left(s_{C}\right)>\pi_{N C S R}^{*}\left(s_{C}\right)$ if $\gamma<1$, and the profits' difference converges to 0 when $\gamma=1$. Moreover, $\pi_{C S R}^{*}\left(s_{C}\right)$ and $\pi_{N C S R}^{*}\left(s_{C}\right)$ are increasing on $\gamma$. These results implies that if $\Pi>\widehat{F}$, there exist two values of $\gamma, \underline{\gamma}<\bar{\gamma}$ such that, for $\gamma<\underline{\gamma}$ only the condition $\gamma \pi_{N C S R}^{*}\left(s_{C}\right)<\widehat{F}$ holds, whereas for $\gamma>\bar{\gamma}$ only the condition $\gamma \pi_{N C S R}^{*}\left(s_{C}\right)>\widehat{F}$ is satisfied. For intermediated values of $\gamma$, both conditions hold.

\section{Proof of Proposition 2:}

Total welfare. Consider the CSR equilibrium. Total welfare $W_{C S R}$ does not depend on prices but on the final allocation of the goods and the costs incurred in their production. Then, since in this equilibrium both the strategic type (which occurs with probability $\theta$ ) and the type $F=0$ (which occurs with probability $\frac{1-\theta}{2}$ ) invest in the clean technology, total welfare is

$$
W_{C S R}=\frac{1+\theta}{2} G \int_{\alpha^{*}}^{1} x h(x) d x-\theta \widehat{F}=\frac{1+\theta}{2} W-\theta \widehat{F},
$$

where when the good is produced with the clean technology (which happens with probability $\frac{1+\theta}{2}$ ) consumers obtain utility $W \equiv G \int_{\alpha^{*}}^{1} x h(x) d x$. With probability $\theta$ the firm is strategic and it has to incur in a cost $\widehat{F}$. If the firm produces with the dirty technology, consumers do not obtain additional utility, and there is a monetary (price) transfer from consumers to the firm that do not have total welfare implications. 
Similarly, consider the NCSR equilibrium, with total welfare $W_{N C S R}=\frac{1-\theta}{2} G \int_{\alpha^{*}}^{1} x h(x) d x=$ $\frac{1-\theta}{2} W$

Then, it is easy to compute $W_{C S R}-W_{N C S R}=\theta(W-\widehat{F})>0$ since we are assuming $\widehat{F}<\Pi<$ W.

Profits. Exante firm profits in the CSR equilibrium are $\Pi_{C S R}=\left(\frac{1+\theta}{2}+\frac{1-\theta}{2}(1-\gamma)\right) \pi_{C S R}^{*}\left(s_{C}\right)-$ $\theta \widehat{F}$; namely, the probability of obtaining a clean signal multiplied by its value, minus the expected cost of investing in the clean technology (which is relevant only for the strategic type). Plugging $\pi_{C S R}^{*}\left(s_{C}\right)=\frac{(1+\theta) \Pi}{2-\gamma(1-\theta)}$ into the previous expression, and simplifying, we obtain $\Pi_{C S R}=$ $\frac{1+\theta}{2} \Pi-\theta \widehat{F}$. Similarly, in the case of the NCSR equilibrium, the expected firm profits are $\Pi_{N C S R}=$ $\left(\frac{1-\theta}{2}+\frac{1+\theta}{2}(1-\gamma)\right) \pi_{N C S R}^{*}\left(s_{C}\right)$. Plugging $\pi_{N C S R}^{*}\left(s_{C}\right)=\frac{(1-\theta) \Pi}{2-\gamma(1+\theta)}$ into the expression, and simplifying, we obtain $\Pi_{N C S R}=\frac{1-\theta}{2} \Pi$. It is now easy to show that $\Pi_{C S R}-\Pi_{N C S R}=\theta(\Pi-\widehat{F})>0$.

Consumer surplus. Finally, consumer surplus can be computed by subtracting profits $\Pi$ from total welfare $W$ in both equilibria, leading to $C S_{C S R}=\frac{1+\theta}{2}(W-\Pi)$ and $C S_{N C S R}=\frac{1-\theta}{2}(W-\Pi)$. Again we obtain that $C S_{C S R}-C S_{N C S R}=\theta(W-\Pi)>0$. This concludes the proof.

Proof of Proposition 3: $\Pi^{\prime}=\left[1-H^{\prime}\left(\alpha^{* *}\right)\right] G \alpha^{\prime *}$ where $\alpha^{\prime *} \in \arg \max \left\{\left[1-H^{\prime}(r)\right] G r\right\}$. Notice that

$$
\Pi^{\prime}=\left[1-H^{\prime}\left(\alpha^{*}\right)\right] G \alpha^{*} \geq\left[1-H^{\prime}\left(\alpha^{*}\right)\right] G \alpha^{*} \geq\left[1-H\left(\alpha^{*}\right)\right] G \alpha^{*}=\Pi .
$$

This implies that, $\pi_{C S R}^{\prime *}\left(s_{C}\right)=\frac{(1+\theta) \Pi^{\prime}}{2-\gamma(1-\theta)} \geq \pi_{C S R}^{*}\left(s_{C}\right)=\frac{(1+\theta) \Pi}{2-\gamma(1-\theta)}$. For the same token, $\pi_{N C S R}^{\prime *}\left(s_{C}\right) \geq$ $\pi_{N C S R}^{*}\left(s_{C}\right)$. The proposition follows for the previous results and the equilibrium conditions.

Proof of Proposition 4: As the non strategic type with $F=\infty$ will manipulate, the value of a good signal, $\pi_{C S R}^{*}\left(s_{C}\right)$, decreases from $\frac{(1+\theta) \Pi}{2-\gamma(1-\theta)}$ to $\frac{(1+\theta) \Pi}{2-\gamma^{\prime}(1-\theta)}$. Moreover, manipulation make more attractive to deviate since the good signal is more likely, then the condition of the equilibrium becomes:

$$
\pi_{C S R}^{*}\left(s_{C}\right)-\widehat{F} \geq \operatorname{Pr}\left(s_{C} \mid D\right) \pi_{C}^{*}\left(s_{C}\right)=\left(1-\gamma^{\prime}\right) \pi_{C S R}^{*}\left(s_{C}\right)
$$

Then

$$
\gamma^{\prime} \pi_{C S R}^{*}\left(s_{C}\right)=\frac{\gamma^{\prime}(1+\theta) \Pi}{2-\gamma^{\prime}(1-\theta)} \geq \widehat{F}
$$


This condition is more difficult to be satisfied than $\frac{\gamma(1+\theta) \Pi}{2-\gamma(1-\theta)} \geq \widehat{F}$, because $\frac{\gamma(1+\theta) \Pi}{2-\gamma(1-\theta)} \geq \frac{\gamma^{\prime}(1+\theta) \Pi}{2-\gamma^{\prime}(1-\theta)}$.

Proof of Lemma 3: Take for example the limit firm with fixed cost equal to $\frac{\gamma^{\prime}(1+\theta) \Pi}{2-\gamma^{\prime}(1-\theta)}+\varepsilon$, the payoff of this firm in the CSR equilibrium is $\frac{(1+\theta) \Pi}{2-\gamma(1-\theta)}-\frac{\gamma^{\prime}(1+\theta) \Pi}{2-\gamma^{\prime}(1-\theta)}$ which is higher than its payoff in the NCSR equilibrium $\frac{\left(1-\gamma^{\prime}\right)(1-\theta) \Pi}{2-\gamma^{\prime}(1+\theta)}$ :

$$
\frac{(1+\theta) \Pi}{2-\gamma(1-\theta)}-\frac{\gamma^{\prime}(1+\theta) \Pi}{2-\gamma^{\prime}(1-\theta)}>\frac{\left(1-\gamma^{\prime}\right)(1+\theta) \Pi}{2-\gamma(1-\theta)}>\frac{\left(1-\gamma^{\prime}\right)(1-\theta) \Pi}{2-\gamma^{\prime}(1+\theta)}
$$

The last inequality, follows from

$$
\frac{\left(1-\gamma^{\prime}\right)(1+\theta) \Pi\left(2-\gamma^{\prime}(1+\theta)\right)}{(2-\gamma(1-\theta))\left(2-\gamma^{\prime}(1+\theta)\right)}>\frac{\left(1-\gamma^{\prime}\right)(1-\theta) \Pi(2-\gamma(1-\theta))}{\left(2-\gamma^{\prime}(1+\theta)\right)(2-\gamma(1-\theta))}
$$

Then

$$
(1+\theta)\left(2-\gamma^{\prime}(1+\theta)\right)>(1-\theta)(2-\gamma(1-\theta))
$$

which simplifies to

$$
2(1+\theta)-\gamma^{\prime}\left(1+2 \theta+\theta^{2}\right)>2(1-\theta)-\gamma\left(1-2 \theta+\theta^{2}\right)
$$

And finally

$$
\left(\gamma-\gamma^{\prime}\right)\left(1+\theta^{2}\right)+2 \theta\left(2-\gamma^{\prime}-\gamma\right)>0
$$

This is true given that $1 \geq \gamma>\gamma^{\prime}$.

Proof of Proposition 5: The belief system is consistent with the strategies played in equilibrium. Then we have to check that such strategies are optimal given the belief system and the conditions established in the Proposition 5. First, notice that $\gamma \Pi>\widehat{F} \Longleftrightarrow(1-\gamma) \Pi<\Pi-\widehat{F}$, then there exists a $c$ such that $(1-\gamma) \Pi<c<\Pi-\widehat{F}$. Assuming that $c$ satisfies such a condition, we have to show that neither type wants to separate from the equilibrium. The strategic type gets $\Pi-\widehat{F}-c>0$ on the equilibrium path. He can only deviate from it by not committing and he obtains zero profits, or by committing but choosing the dirty technology, obtaining $(1-\gamma) \Pi-c<0$. Type $F=0$ has less incentives to deviate since he obtains higher profits on the equilibrium path $\Pi-c>0 . F \rightarrow \infty$ obtains zero profits but by deviating and not investing in the clean technology, it would obtain $(1-\gamma) \Pi-c<0$. The second part of the statement comes from 
$\gamma \pi_{C}\left(s_{C}\right)>\widehat{F} \Longrightarrow \gamma \Pi>\widehat{F}$. In order words, if the condition of the CSR equilibrium is satisfied, the condition for separating equilibrium also holds. This concludes the proof.

\section{B Continuous types model}

We keep our benchmark model, but we replace the three types set (with $F=0, F=\widehat{F}$ and $F \rightarrow \infty)$ by a continuous set of types. Consider that the clean technology entails a fixed cost $f \in[0,1]$, where $f$ is distributed according to $G(f)$, whereas the dirty technology entails no fixed cost. In particular, we will focus on the uniform distribution, i.e. $G(f)=f$.

The bayesian equilibrium of this game is characterized by a cut-off type $\widehat{f}$ such that firms invest in the clean technology if $f \leq \widehat{f}$ and not otherwise, and thus the level of CSR is described by $G(\widehat{f})$. Given the payoffs functions characterized in the previous sections, this cut-off type is implicitly defined for the firm being indifferent between investing or not in the clean technology, that is,

$$
\begin{aligned}
\Pi \operatorname{Pr}\left(C \mid s_{C}\right)-\widehat{f} & =(1-\gamma) \Pi \operatorname{Pr}\left(C \mid s_{C}\right), \\
\gamma \Pi \operatorname{Pr}\left(C \mid s_{C}\right) & =\widehat{f} .
\end{aligned}
$$

As types lower than $\widehat{f}$ invest in the clean technology and higher types do not, applying the bayes rule we obtain:

$$
P\left(C \mid s_{C}\right)=\frac{G(\widehat{f})}{G(\widehat{f})+(1-\gamma)(1-G(\widehat{f}))} .
$$

Plugging this expression in the equation that characterizes $\widehat{f}$ we obtain:

$$
\begin{aligned}
\gamma \Pi \frac{G(\widehat{f})}{G(\widehat{f})+(1-\gamma)(1-G(\widehat{f}))} & =\widehat{f} \\
\gamma \Pi G(\widehat{f}) & =G(\widehat{f}) \widehat{f}+(1-\gamma)(1-G(\widehat{f})) \widehat{f} \\
\frac{1-\gamma}{\gamma} & =\frac{G(\widehat{f})}{\widehat{f}}(\Pi-\widehat{f}) .
\end{aligned}
$$

If $\gamma=1$ (i.e. perfect information) the firm invests if $f \leq \Pi$, while if $\gamma=0$ the firm never invests. If $G(f)$ is uniformly distributed over $[0,1]$ we can explicitly characterize the cut-off type 
and, accordingly, the percentage of firms that decide to be SR:

$$
\widehat{f}=\Pi-\frac{1-\gamma}{\gamma}
$$

Then, it is easy to see that $\widehat{f}$ is increasing in $\Pi$ and $\gamma$, which implies that propositions 1 and 3 also hold with continuous fixed cost types.

\section{Pooling Equilibrium}

In this appendix we analyze the case in which the commitment decision is costless, $c=0$. In such a case the only perfect bayesian equilibria are pooling equilibria.

LEMMA 4 If $c=0$, the perfect bayesian equilibria in pure strategies must be a pooling equilibria in which all types of firms follow the same strategy regarding the commitment decision.

Proof: In order to rule out the partially separating equilibrium (given that we have two possible strategies and three types) we have to consider several cases.

i) Consider that $F=0$ chooses $d_{0}=C o$ and the other two types $d_{\widehat{F}}=d_{\infty}=N C o$. Thus $P\left(C \mid s_{C}, \lambda\left(s_{C}, C o\right)\right)=1$. There are two cases. If the strategic type in equilibrium chooses a dirty technology, then $P\left(C \mid s_{C}, \lambda\left(s_{C}, N C o\right)\right)=0$ and both types $F=\widehat{F}$ and $F=\infty$ are willing to mimic $F=0$. If the strategic type chooses a clean technology, then it would increases its profits by mimicking $F=0$ and choosing $d_{\widehat{F}}=C o$.

ii) Consider that $F=0$ chooses $d_{0}=N C o$ and the other two types $d=C o$, then $P\left(C \mid s_{C}, \lambda\left(s_{C}, N C o\right)\right)=$ 1. Thus the other two types are better by deviating and mimicking $F=0$.

iii) Consider that $F=\infty$ chooses $d_{\infty}=N C o$ and the other two types $d=C o$, then $P\left(C \mid s_{C}, \lambda\left(s_{C}, N C o\right)\right)=0$ and the profits of $F=\infty$ will be 0 . Therefore, $F=\infty$ would be better by deviating and mimicking the other two types.

iv) The case in which $F=\infty$ chooses $d_{\infty}=C o$ and the other two types $d=N C o$ is completely analogous to case iii). 
v) Consider now that the strategic type chooses a different strategy than the other two, there are two possibilities. First, the strategic type chooses a clean technology, then $P\left(C \mid s_{C} \lambda\left(s_{C}, d_{\widehat{F}}\right)\right)=$ 1 and $F=0$ would prefer to mimic the strategic type, as in the last case of i). Second, the strategic type chooses a dirty technology but then, the posterior belief will be $P\left(C \mid s_{C} \lambda\left(s_{C}, d_{\widehat{F}}\right)\right)=1$ and its profits will be 0 . In this case, the strategic type would be better by deviating and by mimicking the other two types, as in case iii).

Finally, the pooling equilibrium on any strategy $C$ and $N C$ is always an equilibrium because we can have arbitrary believes out of the equilibrium path, in particular $\lambda_{\infty}\left(s_{C},.\right)=1$.

The intuition why a separating equilibrium does not exist is as follows. There does not exist a separating equilibrium in which the type $F=\infty$ chooses a different strategy than the other two types since, independently of the realization of the signal, it would not get any profits and mimicking the type $F=0$ generates positive profits. In summary, $F=\infty$ has incentives to be with the other two types. For the opposite argument, there does not exist a separating equilibrium in which the type $F=0$ chooses a different strategy than the other two types, since the other two types have incentives to mimic $F=0$. Finally, there does not exist a separating equilibrium in which the strategic type chooses a different strategy than the other two types: the strategic type, depending on the parameters, has the same preferences than $F=0$ or $F=\infty$, which implies that the previous arguments apply. ${ }^{25}$

Focusing thus in the pooling equilibria, we can construct two pooling equilibria in which the three types choose either to commit or not to commit, beliefs on the equilibrium path are the priors and consumers have a belief outside of the equilibrium path $\lambda(\infty \mid d, s)=1$ (namely, a deviating firm is $F=\infty$ ). However, it seems less natural an equilibrium in which "good" firms lose the opportunity to differentiate through commitment. In fact, as we state in the next proposition, this equilibrium may not pass the intuitive criterium of Cho-Kreps.

\footnotetext{
${ }^{25}$ The previous arguments and Proposition 4 depend on the fact that we assume that it is costless to commit to not manipulate. It is very intuitive to see that if we introduced a cost of committing, separation equilibria might arise. For example, consider a constelation of parameters such that firms with $F=0$ and $F=\widehat{F}$ choose the clean technology and committing has a cost $c$. Then, if $\pi_{C}^{*}\left(s_{C}\right)-\widehat{F} \geq c \geq(1-\gamma) \pi_{C}^{*}\left(s_{C}\right)$ we could build a separating equilibrium in which firms with $F=0$ and $F=\widehat{F}$ would commit to not manipulate, whereas a firm with $F=\infty$ would not commit. Notice that such an equilibrium would have $\lambda(\infty \mid N C o, s)=1$.
} 
Proposition 7 The pooling equilibrium in which all types of firms follow a commitment strategy is the only perfect bayesian equilibrium that satisfies the intuitive criterium of Cho-Kreps for all parameter values.

Proof: The pooling equilibrium in which all the types choose $C o$, posterior believes on equilibrium path are equal to priors believes and the belief out of the equilibrium path is $\lambda_{\infty}(N C,)=$.1 , is a perfect Bayesian equilibrium and satisfies the intuitive criterion of Cho-Kreps. The first part, is direct because independently of the realization of the signal, the profits of the firm when choosing $N C$ are 0 . Then, all the types prefer $C o$ to $N C$. Moreover, this equilibrium satisfies the Cho-Kreps criterion since the maximum payoff of type $F=\infty$ are achieved with $N C$ and $\lambda_{0}(N C,)=$.1 , then we cannot rule out the belief $\lambda_{\infty}(N C,)=$.1 .

The pooling equilibrium in which all the types choose $N C o$, posterior believes on equilibrium path are equal to priors believes and the belief out of the equilibrium path is $\lambda_{\infty}(C o,)=$.1 , is a perfect Bayesian equilibrium but for some parameters does not satisfy the intuitive criterion of Cho-Kreps. In particular, consider that parameters are such that the strategic type chooses a clean technology and does not have incentives to manipulate. Then, the equilibrium payoff of the $F=\infty$ type on the equilibrium path is $\frac{\left(1-\gamma^{\prime}\right)(1+\theta) \Pi}{2-\gamma^{\prime}(1-\theta)}$. Then, if $\frac{\left(1-\gamma^{\prime}\right)(1+\theta) \Pi}{2-\gamma^{\prime}(1-\theta)}>(1-\gamma) \Pi$, type $F=\infty$ will be better in the equilibrium path than choosing $C o$ with the most favorable belief $\lambda_{0}(C o,)=$.1 . This rule out $\lambda_{\infty}(C o,)=$.1 and consequently the previous pooling equilibrium.

The pooling equilibria requires beliefs out of the equilibrium path that give more weight (probabilities) to the types that will produce with a dirty technology. However, the intuitive criterium of Cho \& Kreps allows us to show that good types $(F=0$ and strategic types producing with the clean technology) may find it optimal to deviate from the pooling equilibrium in which all the types choose $N C$. The intuitive criterium establishes two conditions to eliminate a perfect bayesian equilibrium. First, that the type that deviates obtains larger profits out of the equilibrium path if it is identified for his true type. In our case, if for example, type $F=0$ would obtain larger profits by choosing $C o$ and being identified as type $F=0$, that it is obtaining with $N C$ and pooled with $F=\infty$. 
Second, and applying the requirement to our model, the bad types $(F=\infty$ and strategic types producing with the dirty technology) may obtain larger profits in the equilibrium path $(\mathrm{NCo})$ that out of the equilibrium path for all possible beliefs. In our case, this implies that they must obtain larger profits by being pooled with the good types and having the opportunity to manipulate than by commiting to not manipulate (obtaining with lower probability a low signal) with the more favorable beliefs $\lambda\left(0 \mid C o, s_{C}\right)=1$ (that is, being taken as an $F=0$ ), this second condition is satisfied only if manipulating is a suficiently attractive, that is, if $\gamma-\gamma^{\prime}$ is large enough.

There exist alternative institutional arrangements to cope with the problems derived from the possibility of manipulating the ifnormation by the firm. Namely, we have mentioned transprency regulaiton by the public sector and self-commitment by the firm through external agents. The analysis in the previous subsection allows us to discuss the interaction between such institutional arrangements in the following corollary:

COROLlary 8 Transparency regulation that reduces the distance between $\gamma$ and $\gamma^{\prime}$ is a strategic substitute of self-commitment to transparency by firms.

Proof: This is due to the fact that the condition for ruling out the pooling equilibrium on $N C$, $\frac{\left(1-\gamma^{\prime}\right)(1+\theta) \Pi}{2-\gamma^{\prime}(1-\theta)}>(1-\gamma) \Pi$, is likely to be satisfied when $\gamma-\gamma^{\prime}$ is large, since both sides of the inequality are decreasing.

We do this statement in the sense that only when $\gamma-\gamma^{\prime}$ is large enough, we can guarantee that the only equilibrium in pure strategies (that satisfies the intuitive criterium) is the pooling equilibrium in which all types of firms follow a commitment strategy.

\section{REFERENCES}

[1] Akerlof, G. (1970), “The Market for 'Lemons': Quality Uncertainty and the Market Mechanism", Quarterly Journal of Economics, 84, 3, 488-500. 
[2] Bagnoli, M. and S. Watts (2003), "Selling to Socially Responsible Consumers: Competition and the Private Provision of Public Goods", Journal of Economics 6 Management Strategy, $12,3,419-445$.

[3] Bagnoli, M. and Watts, S., (2014), "Voluntary Assurance of Voluntary CSR Disclosure". Available at SSRN: http://ssrn.com/abstract=2465400 or http://dx.doi.org/10.2139/ssrn.2465400

[4] Bagnoli, M. and T. Bergstrom (2005), "Log-concave probability and its applications", Economic Theory, 26, 2, 445-469.

[5] Baron, D. (2003), "Private Politics", Journal of Economics and Management Strategy, 21, $31-66$.

[6] Baron, D., (2005), "Competing for the public through the news media", Journal of Economics and Management Strategy.

[7] Baron, D., (2011), "Credence attributes, voluntary organizations, and social pressure", Journal of Public Economics 95, 1331-1338.

[8] Bendell, J., "Chiquita", Case Studies, Business and Sustainable Development, BSDglobal.com, as visited March 2010.

[9] Besley, T. and M. Ghatak (2007), "Retailing public goods: The economics of corporate social responsibility", Journal of Public Economics, vol. 91(9), pages 1645-1663, September.

[10] Bottega, L and J. de Freitas (2009), "Public, Private and Nonprofit Regulation for Environmental Quality", Journal of Economics and Management Strategy, Volume 18 Issue 1.

[11] Brugmann, J. and CK Prahalad, (2007), "Cocreating Business's New Social Compact", Harvard Business Review, February.

[12] Calveras, A. and JJ Ganuza (2014): "External and internal corporate social responsibility: complementarities through product quality", mimeo. 
[13] Calveras, A. and JJ Ganuza (2014): "The role of public information in corporate social responsibility", Barcelona GSE working paper.

[14] Cashore, B., G. Auld, and D. Newson, (2005), Governing through Markets: Forest Certification and the Emergence of Non-State Authority, New Haven, CT: Yale University Press.

[15] Casadesus-Masanell, R., M. Crooke, F. Reinhardt, and V. Vasishth, (2009), "Households' Willingness to Pay for 'Green' Goods: Evidence from Patagonia's Introduction of Organic Cotton Sportswear", Journal of Economics and Management Strategy. 18: 203-233.

[16] Crawford, V.P. and J. Sobel (1982), "Strategic Information Transmission", Econometrica,50,1431-1451.

[17] Dulleck, U. and R. Kerschbamer (2006): "On Doctors, Mechanics, and Computer Specialists: The Economics of Credence Goods", Journal of Economic Literature, Vol. 44, No. 1, pp. 5-42

[18] Diamond, D., (1989), "Reputation acquisition in debt markets", Journal of Political Economy, vol. 97 n 41.

[19] Dyck, A. and L. Zingales (2002), "The Corporate Governance Role of the Media", in R. Islam: The Right to Tell: The Role of Mass Media in Economic Development. Washington, D.C.: World Bank, 2002, pp. 107-40.

[20] Dye, R.A (1985), "Disclosure of Nonproprietary Information", Journal of Accounting Research, 23, 123-145.

[21] Elfenbein, D., Ray Fisman, R. and B. McManus, (2012): "Charity as a substitute for reputation: Evidence from an online marketplace", Review of Economic Studies Volume 79, Issue 4.

[22] Emons,W. (1997): "Credence Goods and Fraudulent Experts", RAND Journal of Economics 2, 8(1):1 07-19. 
[23] Farrell, J and M. Rabin (1996), "Cheap Talk", Journal of Economic Perspectives, 10, 3, 103-118.

[24] Feddersen, T.J. and T.W. Gilligan (2001), "Saints and Markets: Activists and the Supply of Credence Goods," Journal of Economics and Management Strategy, 10(1), 149-171.

[25] Fudenberg, D. and J. Tirole (1991), Game Theory, MIT Press.

[26] Glazer, J. and A. Rubinstein (2004), "On Optimal Rules of Persuasion", Econometrica, 72, $1715-1736$.

[27] Grossman, S.J. (1981), "The Informational Role of Warranties and Private Disclosure about Product Quality", Journal of Law and Economics, 24, 561-483.

[28] Heal, G. (2008), When principles pay, Columbia University Press.

[29] Hiscox, Michael J. and Nicholas F.B. Smyth (2006), "Is There Consumer Demand for Improved Labor Standards? Evidence from Field Experiments in Social Product Labeling." Working paper, Harvard University.

[30] Mohr, L.A., D.J. Webb, and K. Harris (2001), "Do Consumers Expect Companies to Be Socially Responsible? The Impact of Corporate Social Responsability on Buying Behavior," Journal of Consumer Affairs, 35(1), 45-72.

[31] Murray, K. and C. Volgel, (1997), "Using a Hierarchy of Effects Approach to Gauge the Effectiveness of Corporate Social Responsability to Generate Goodwill Toward the Firm: Financial versus Nonfinancial Impacts," Journal of Business Research, 38.

[32] Nelson, P. (1970), "Information and consumer behaviour"; Journal of Political Economy 78: 311-329.

[33] Shin, H.S (1994), "The Burden of Proof in a Game of Persuasion", Journal of Economic Theory, 64, 253-264. 
[34] Tirole, J. (1988), The theory of industrial organization, MIT Press.

[35] Wolinsky, A. (1993): "Competition in a Market for Informed Experts' Services", RAND Journal of Economics, 24(3): 380-98.

[36] Wolinsky, A. (1995): "Competition in Markets for Credence Goods", Journal of Institutional and Theoretical Economics,1 51(1): 117-31.

[37] Xia, J., J. Wang, Y. Wang, and Xing, R. (2008), "Stakeholder pressures and the global diffusion of the ISO 14001 inititative: a resource dependence perspective", International Journal of Sustainable Society, vol. 1, $\mathrm{n}^{\circ} 1$.

[38] Yaziji, Michael, 2004: "Turning gadflies into allies", Harvard Business Review February 2004. 
FIGURE 1

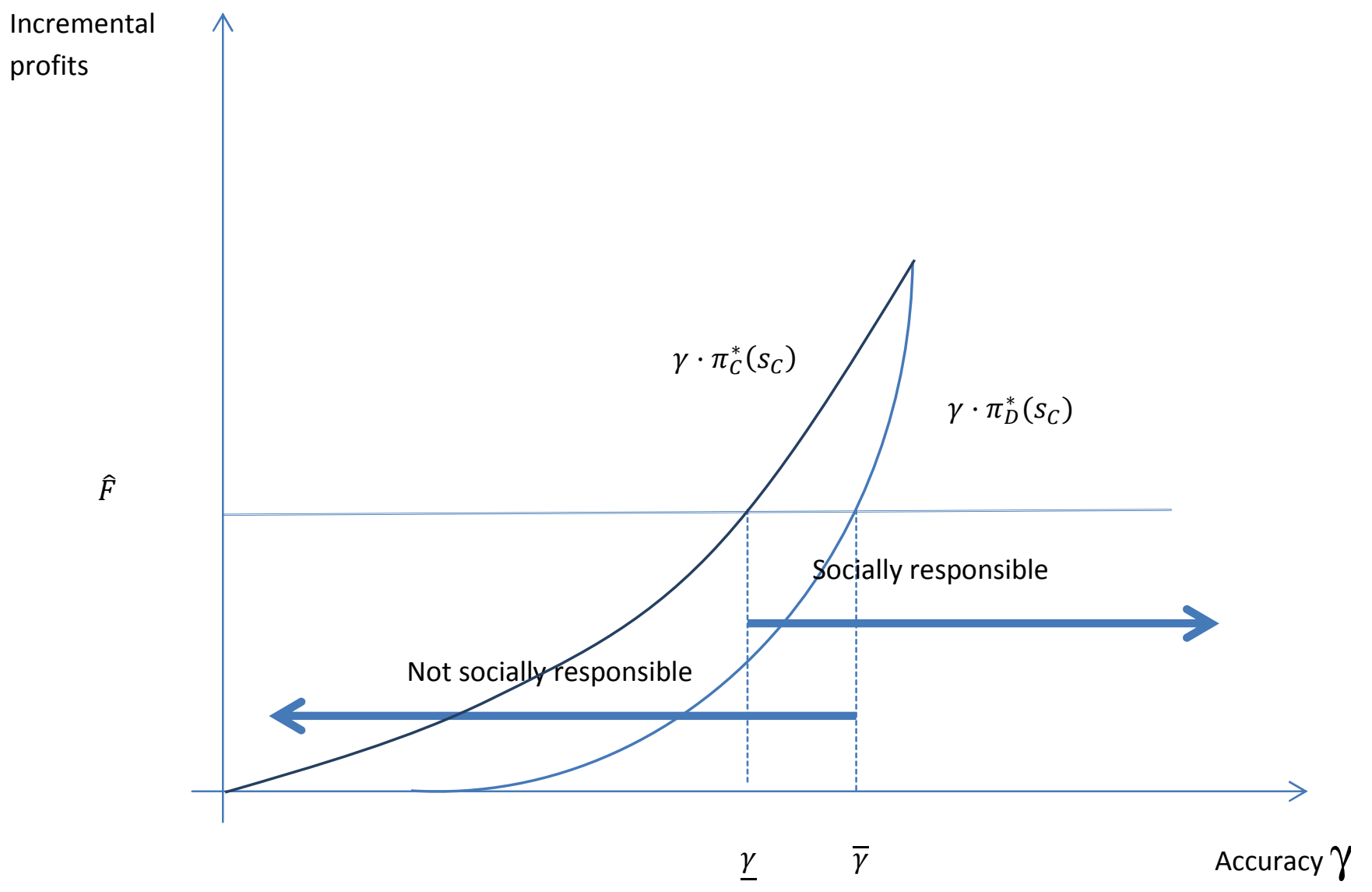

